\title{
Enhanced heat transfer in tubes based on vascular heat exchangers in fish: Experimental investigation
}

Navickait, Kristina; Mocerino, Andrea; Cattani, Luca; Bozzoli, Fabio; Bahl, Christian; Liltrop, Klaus; Zhang, Xiaodan; Engelbrecht, Kurt

Published in:

International Journal of Heat and Mass Transfer

Link to article, DOI:

10.1016/j.jheatmasstransfer.2019.03.067

Publication date:

2019

Document Version

Peer reviewed version

Link back to DTU Orbit

Citation (APA):

Navickait, K., Mocerino, A., Cattani, L., Bozzoli, F., Bahl, C., Liltrop, K., Zhang, X., \& Engelbrecht, K. (2019). Enhanced heat transfer in tubes based on vascular heat exchangers in fish: Experimental investigation. International Journal of Heat and Mass Transfer, 137, 192-203.

https://doi.org/10.1016/j.ijheatmasstransfer.2019.03.067

\section{General rights}

Copyright and moral rights for the publications made accessible in the public portal are retained by the authors and/or other copyright owners and it is a condition of accessing publications that users recognise and abide by the legal requirements associated with these rights.

- Users may download and print one copy of any publication from the public portal for the purpose of private study or research.

- You may not further distribute the material or use it for any profit-making activity or commercial gain

- You may freely distribute the URL identifying the publication in the public portal 


\title{
Enhanced heat transfer in tubes based on vascular heat exchangers in fish: experimental investigation
}

\author{
Kristina Navickaitè ${ }^{1}$, Andrea Mocerino², Luca Cattani ${ }^{3}$, Fabio Bozzoli ${ }^{2,4}$, Christian Bahl ${ }^{1}$, \\ Klaus Liltrop ${ }^{5}$, Xiaodan Zhang ${ }^{5}$, Kurt Engelbrecht ${ }^{1 *}$ \\ ${ }^{I}$ Technical University of Denmark, Department of Energy Conversion and Storage, Frederiksborgvej
} 399, 4000 Roskilde, Denmark

${ }^{2}$ Department of Engineering and Architecture, University of Parma, Parco Area delle Scienze 181/A, 43121, Parma, Italy

${ }^{3}$ CIDEA, Interdepartmental Centre, University of Parma, Parco Area delle Scienze 181/A, I-43124 Parma, Italy

${ }^{4}$ SITEIA.PARMA Interdepartmental Centre, University of Parma, Parco Area delle Scienze 181/A, I43124 Parma, Italy

${ }^{5}$ Technical University of Denmark, Department of Mechanical engineering, Nils Koppels Allé 404, 2800 Kgs. Lyngby, Denmark

*kuen@dtu.dk

Abstract. A double corrugated tube geometry for improved heat transfer performance inspired by vascular heat exchangers found in fish such as the tuna and the opah is presented. The geometry features a cross section that varies continuously in the flow direction while maintaining a constant hydraulic diameter, which gives enhanced heat transfer at a relatively low increase in pressure drop. Five ellipse-based tubes with varying corrugation severity and period that emulate blood vessels of fish were produced in an aluminium alloy using additive manufacturing technology. Thermal performance of the novel tube design was experimentally investigated in a counter flow tube-in-shell heat exchanger in a range of Reynold numbers from 1000 to 2500. Correlations for the Nusselt number and friction factor for each tube are proposed and the experimental results show that Nusselt number increases up to $500 \%$ in corrugated tubes compared to a straight tube. The global thermo-hydraulic performance, evaluated for the same pumping power, of the double corrugated tubes is up to $160 \%$ higher than of a straight tube.

Keywords. Vascular heat exchanger, double corrugation, high performance heat transfer devices, biomimetic, modified Wilson plot, Nusselt number correlation

\section{Nomenclature}

\begin{tabular}{|c|c|}
\hline \multicolumn{2}{|c|}{ Variables } \\
\hline$A R$ & Aspect ratio, [-] \\
\hline$A_{c}$ & Cross-section area, $\left[\mathrm{m}^{2}\right]$ \\
\hline$A_{s}$ & Surface area, $\left[\mathrm{m}^{2}\right]$ \\
\hline$C$ & Multiplicative constant, [-] \\
\hline$c_{p}$ & Specific heat, $\left[\mathrm{J}(\mathrm{kg} \mathrm{K})^{-1}\right]$ \\
\hline$D$ & Diameter, $[\mathrm{m}]$ \\
\hline$f$ & Friction factor, $[-]$ \\
\hline$h$ & Convection coefficient, $\left[\mathrm{W}\left(\mathrm{m}^{2} \mathrm{~K}\right)^{-1}\right]$ \\
\hline$K_{L}$ & Minor pressure losses coefficient, [-] \\
\hline$k$ & Thermal conductivity, $\left[\mathrm{W}\left(\mathrm{m} \mathrm{K}^{-1}\right]\right.$ \\
\hline$L$ & Length, $[\mathrm{m}]$ \\
\hline$N$ & Number of experiments, [-] \\
\hline$N u$ & Nusselt number, [-] \\
\hline PEC & Performance evaluation criteria, [-] \\
\hline $\operatorname{Pr}$ & Prandtl number, $[-]$ \\
\hline$p$ & Corrugation period, $[\mathrm{m}]$ \\
\hline
\end{tabular}

\begin{tabular}{|l|l|}
\hline$Q$ & Heat transfer, $[\mathrm{W}]$ \\
\hline$R$ & Radius, [m] \\
\hline$R e$ & Reynolds number, $[-]$ \\
\hline$R_{w}$ & Thermal wall resistance, $\left[\mathrm{m}^{2} \mathrm{KW}^{-1}\right]$ \\
\hline$S_{q}$ & Root square mean surface roughness, $[\mathrm{m}]$ \\
\hline$U$ & Overall heat transfer coefficient, $\left[\mathrm{W}\left(\mathrm{m}^{2} \mathrm{~K}\right)^{-1}\right]$ \\
\hline$Y$ & The twist ratio, $[-]$ \\
\hline$x, y, z$ & Geometric coordinates, $[\mathrm{m}]$ \\
\hline$w$ & Fluid flow velocity, $\left[\mathrm{m} \mathrm{s}^{-1}\right]$ \\
\hline$\Delta T$ & Temperature difference, $[\mathrm{K}]$ \\
\hline$\Delta T_{l m}$ & Logarithmic mean temperature difference, $[\mathrm{K}]$ \\
\hline$\Delta p$ & Pressure difference, $[\mathrm{Pa}]$ \\
\hline \multicolumn{1}{|c|}{$A b b r e v i a t i o n s$} \\
\hline AEA & Alternating elliptical axis \\
\hline CFD & Computational fluid dynamics \\
\hline HST & Helical screw-tape \\
\hline OD & Outer diameter, [m] \\
\hline
\end{tabular}




\begin{tabular}{|l|l|}
\hline T & Thermocouple \\
\hline \multicolumn{2}{|c|}{ Greek letters } \\
\hline$\alpha$ & Re exponent, $[-]$ \\
\hline$\beta$ & Pr exponent, [-] \\
\hline$\delta$ & $\begin{array}{l}\text { Wall thickness, [m]; } \\
\text { standard error of estimate, }[-]\end{array}$ \\
\hline$\xi$ & Vorticity, [-] \\
\hline$\mu$ & Dynamic viscosity, [Pa s] \\
\hline$\rho$ & Density, [kg m$\left.{ }^{-3}\right]$ \\
\hline \multicolumn{2}{|c|}{ Subscripts } \\
\hline cal & Calculated \\
\hline
\end{tabular}

\begin{tabular}{|l|l|}
\hline est & Estimate \\
\hline exp & Experimental \\
\hline $\mathrm{f}$ & Fluid \\
\hline $\mathrm{h}$ & Hydraulic \\
\hline $\mathrm{i}$ & Inner (tube side) \\
\hline in & Inlet \\
\hline $\mathrm{m}$ & Mean \\
\hline o & Outer (shell side) \\
\hline out & Outlet \\
\hline $\mathrm{s}$ & Shell side \\
\hline $\mathrm{t}$ & Tube side \\
\hline 0 & Straight (reference) \\
\hline
\end{tabular}

1. Introduction

Nature can be an excellent source of inspiration for advanced structures, designs and materials, and the approach is referred to as biomimetics [1]. According to Mattheck [2], as early as 1893, it was suggested by K. Metzger that trees grow in a way that results in an even stress distribution throughout their structure. For example, the concept of even stress flow in mechanical systems has resulted in numerical models that can explain how trees grow and adapt to their unique loading case, including how root systems grow. Flies, beetles, spiders and geckos have specialized attachment geometries on their skin that allow them to climb up smooth vertical surfaces [3], and sharks have small riblets on their skin that reduce drag [4]. In this article, we look to nature for examples of advanced heat exchanger designs, although there are relatively few examples of biological systems that require high heat transfer performance. Many examples of complex thermal insulation techniques can be found in nature, but cases where high heat transfer is required are less common. Examples of insulation techniques include the fur of arctic animals or the insulating blubber layer found on seals and whales [5]. Some examples of high heat transfer performance in nature include the feet of some birds that have a counter-flow heat exchanger composed of blood vessels entering and exiting the feet [6]. This heat exchanger allows the feet to operate at a lower temperature than the rest of the bird's body and thus eliminates the need for insulation, in the form of feathers, on the feet. The counter-flow vascular heat exchanger at the core of several fish species, such as lamnidae sharks and tuna [7] and opahs [8] also represents a compact, high performance heat exchanger. This heat exchanger recovers heat generated in the fish's muscles that is carried in the blood before it is pumped to the gills where the heat is rejected to the surroundings, giving these fish the unique ability to maintain a body temperature that is significantly higher than their surroundings. This heat recovery technique allows them to hunt in waters with lower temperatures than fish without the regenerative heat exchanger. Vascular heat exchangers in fish are fascinating and often complex. For example, the heat exchanger section of a $1.9 \mathrm{~kg}$ skipjack tuna was found to have over 250,000 blood flow passages with two distinct diameters of approximately $0.036 \mathrm{~mm}$ and $0.084 \mathrm{~mm}$ [9]. A photo of blood vessels that comprise part of the counter-flow heat exchanger of an opah is shown in Figure 1(a), and a photo of a skipjack tuna heat recovery vascular system from ref. [9] shows a similar geometry. In Figure 1(a), it can be seen that some blood vessels are nearly circular, others resemble ellipses, and others are irregular. Cross-sections such as shown in Figure 1(a) only show the geometry at one plane in the heat exchangers, and it is not known how the cross section of these blood vessels behaves along the flow direction. To get an idea of how these blood vessels might behave in 3D, we can look at imaging of larger blood vessels. Börnert and Jensen, [10] present a 3D image of coronary arteries shown in Figure 1(b) using magnetic resonance imaging. In the 3D reconstruction, the shape of the arteries seems to fluctuate along the flow path but we assume that the area for flow stays nearly constant to prevent any high flow resistance areas, which would cause stress on the heart. 


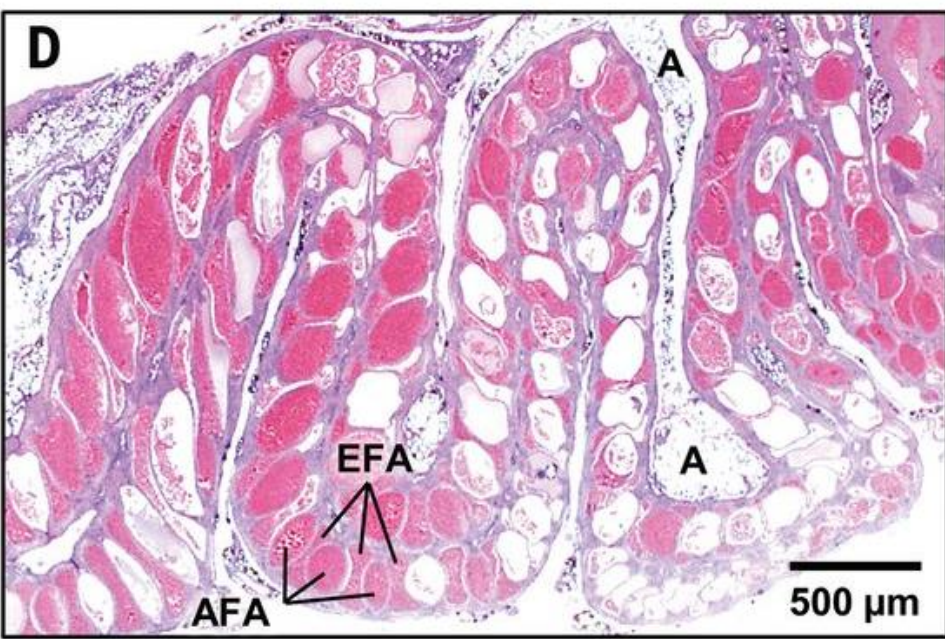

(a)

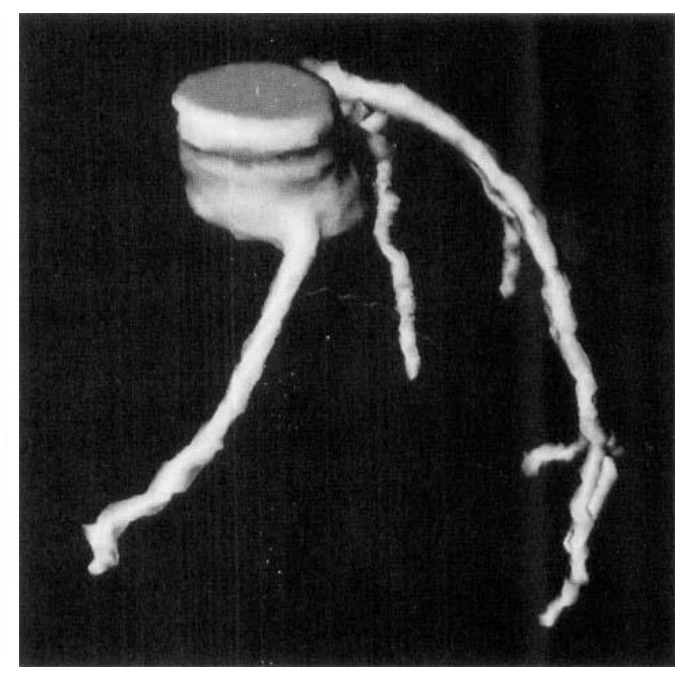

(b)

Figure 1. Photo of blood vessels in the rete mirabile (a), which is located in the gill of the opah. Reproduced with the permission from ref. [8]. MRI image of coronary arteries (b), reproduced with the permission from ref. [10]

Based on the images in Figure 1 and using fish such as the tuna and opah as inspiration, we suggest a double corrugated tube geometry for enhanced heat transfer at a relatively low increase in pressure drop. The proposed flow cross-section is elliptical and constantly changes aspect along the flow path in order to continuously break up the thermal boundary layer that attempts to form in the fluid flow, while maintaining a constant hydraulic diameter. A similar concept was proposed by Jantsch, [11] where the proposed tube was deformed to change the cross sectional shape while maintaining a constant flow area. Jantsch, [11] claimed that the geometry gave "an effective kneading of the fluid in the column" that improved contact between the tube wall and fluid. However, no evidence that Jantsch's invention was demonstrated or tested could be found.

While nature shows quite rare examples where enhanced heat transfer is necessary, the request for such techniques is huge in industry. With growing energy consumptions, the appeal for more efficient techniques to use the available energy is increasing constantly. The food industry, aerospace, paint production, naval, chemical engineering, and paper manufacturing are only few examples where enhanced heat transfer is in high demand [12-18]. In most applications, laminar flow or viscous fluids are required and that reduces the thermal efficiency of such processes or apparatuses.

Many attempts using different techniques to enhance the heat transfer have been reported in literature. Webb and Kim, [15] suggested to classify the methods into active, passive and combined techniques. Active heat transfer enhancement techniques use an external mechanical aid or electrostatic field, fluid vibration or injections, to increase the thermal performance. Passive techniques involve various inserts in a flow, artificial surface roughness and enhanced surfaces such as fins and various types of corrugation. Combined technique couples both passive and active techniques. Due to the flexibility and low maintenance cost, the passive heat transfer enhancement techniques have been most widely implemented into engineering applications.

Experimental investigation of the thermo-hydraulic performance of spirally or transversally corrugated tubes, inserts that induce secondary flow inside a tube were reported by many authors for different flow regimes and fluids. Zimparov, [19] demonstrated that three start spirally corrugated tubes combined with five twisted tape inserts show superior performance to a straight tube as well as two cases when twisted tapes and spirally corrugated tubes are used separately. Meng et al., [13] experimentally proved that heat transfer in alternating ellipse axis (AEA) tubes increases up to $500 \%$ with a penalty in pressure being up to $350 \%$ when compared with a straight tube. Laohalertdecha and Wongwises, [20] compared experimental results obtained for three helically corrugated tubes with a straight tube for two-phase R-134a flow. The Authors found that the heat transfer and the pressure drop in the corrugated tubes increase with the average fluid quality. The reported increase in heat transfer and pressure drop were $50 \%$ and $70 \%$, respectively. 
Pal and Saha, [21] found that a combination of integral spiral corrugation in a circular duct and twisted tape with oblique teeth provides up to $85 \%$ increased heat transfer at fixed pumping power in a laminar flow of viscous oil compared to a circular duct. Moreover, combining both techniques is more efficient than each heat transfer enhancement method separately. Rainieri and Pagliarini, [12] investigated thermal performance of spirally corrugated tubes for fruit juice with a different sucrose concentration. The Authors showed that corrugation has negligible effect on heat transfer when juice with sucrose concentration of $65^{\circ} \mathrm{Bx}$ is used while 14.7 times higher heat transfer was observed for juice with $12{ }^{\circ} \mathrm{Bx}$. In another study performed by Rainieri et al., [22], it was found that for Reynold numbers $(R e)$ higher than 1000, the thermal performance of the helically coiled corrugated tubes increases up to 25 times with a pressure drop increase up to 3 times. The Authors also concluded that the combination of the two heat transfer techniques is more effective than each of them separately. Mac Nelly et al., [23] investigated single spirally corrugated and cross spirally corrugated tubes using laboratory air in the Re range 4000 to 20000 with a Prandlt number $(P r)$ lower than 1. The Authors concluded that Nusselt number $(\mathrm{Nu})$ increases up to 1.88 times in crossspirally corrugated tubes with increasing $R e$ when compared to a straight one. However, single spirally corrugated tubes showed 1.66 times higher $N u$ value regardless of $R e$. Moreover, increase in pressure drop, as concluded in [23], depends on the corrugation angle in single spirally corrugated tubes while in cross-spirally corrugated tubes pressure drop rose significantly regardless of the corrugation angle. Pethkool et al., [17] reported up to $300 \%$ higher $N u$ values for helically corrugated tubes with the increase in friction factor by 1.93 when compared with a smooth tube. It is interesting to note that the Authors found that $N u$ increases with an increase in the ratio between corrugation period (pitch), $p$, and hydraulic diameter, $D_{h}$. Pethkool et al., [17] also concluded that the thermal performance of the corrugated tubes is higher when $R e$ is lower. Harleß et al., [24] investigated helically corrugated tubes in the $R e$ range from 5000 to 23000 . It was concluded that smaller corrugation angles lead to higher $N u$ when tubes with identical $p$ and corrugation height are considered. Moreover, in the same study it was concluded that the dimensionless severity index, $\phi$, used for quantifying the corrugation geometry is not sufficient to determine the heat transfer and friction characteristics. This finding also agrees with the conclusions derived by Rainieri et al., [25] and later study by Harleß et al., [26].

Modelling of the thermal performance of these tubes has been previously reported [27] for a flow with constant pressure drop and fluid properties. The modelling considered both ellipse-based and super ellipse-based geometries and the ellipse-based tubes were found to give the best performance. Based on the modelling results, five double corrugated tubes that emulate blood vessels of the opah and an equivalent straight tube were manufactured in an aluminium alloy using selective laser melting (SLM). The tubes were tested in a counter-flow tube-in-shell heat exchanger setup. The concept of the double corrugation is similar to AEA tubes. However, the transition in the cross-section along the flow path is smoother for the double corrugated tubes, which should lead to a lower pressure drop. The double corrugated tubes have an elliptical cross section and $D_{\mathrm{h}}$ is held constant along the flow direction. The experimental results are obtained for Re number from 1000 to 2500. The obtained thermal and hydraulic performance results are presented as $N u$ and $f$ correlations.

\section{Experimental methodology}

\subsection{Design and construction of the tubes}

The double corrugated tubes, previously described in [27], and an equivalent straight tube were manufactured using selective laser melting technique in $\mathrm{AlSi}_{10} \mathrm{Mg}$ powders. The relative density of the alloy after SLM process was $99.5 \%$. The external surface of all the tested tubes was manually polished using fine sand paper.

The double corrugated tubes are based on an elliptical cross section that changes aspect ratio $(A R)$ of $x$ and $y$ in the flow direction while maintaining a constant $D_{\mathrm{h}}$ along the $z$-axis. The geometry of the investigated tubes is defined by Eq. (1). The cross section of the tube at any point in the flow 
direction is defined as an ellipse with one axis equal to $x$ and the other equal to $y$, that periodically become equal, forcing the cross-section to be a circle.

$$
\left\{\begin{array}{c}
x=\frac{R}{2} A R^{\left(\sin \left(\frac{2 \pi}{p} z\right)\right)}+\frac{R}{2} \\
y=\frac{R}{2} A R^{\left(-\sin \left(\frac{2 \pi}{p} z\right)\right)}+\frac{R}{2}
\end{array}\right.
$$

where $R$ is the radius of an equivalent straight tube and $p$ is the corrugation period.

As it is mentioned in Introduction, the double corrugated tubes for experimental investigation were selected according to the simulation results. From Figure 1 (a), one can see that the aspect ratio of the blood vessels is in the range from approximately 1 to 2.2 . Therefore, the double corrugated tubes were constructed with corresponding aspect ratio for numerical analysis. Furthermore, simulation results demonstrated that double corrugated tubes with $A R$ of 1.6, 2.0 and 2.2 provides the highest efficiency. Therefore, they were selected for the experimental investigation.

The range of $p$ was selected to be from $p / D_{h} 1$ to 50 . It must be mentioned that it is generally accepted that a tube with $p / D_{h} \geq 10$ is considered smooth. The double corrugated tubes, presented in this article, have $p / D_{h}$ of 1.5 and 4 . In this region, the best performance was observed numerically. Therefore, double corrugate tubes with these parameters were selected for the experimental analysis. Nevertheless, some of the double corrugated tubes, such as $A R=2.2$ and $p=7.5 \mathrm{~mm}$ could not be produced due to technical limitations of SLM technology. The end-result of such a tube would have a significantly thicker wall than the rest of the investigated tubes. Thus, a fair comparison of the performance would not be possible.

The geometries for additive manufacturing process were drawn using the Parametric equation tool and Lofted Boss/Base feature build in CAD software, which approximated Eq. (1) for $D_{\mathrm{h}}$ with a maximum inaccuracy of $\pm 3.6 \%$. The manufacturing process adds additional geometrical uncertainty, but it has not been characterized. It is noticeable that the inaccuracy decreases with decreasing $A R$ or increasing $p$. For further discussion, it is assumed that $D_{\mathrm{h}}$ is constant across the flow channel and equivalent to the straight tube. The geometrical data and the nominal inaccuracy in $D_{\mathrm{h}}$ of the tested tubes are given in Table 1.

Table 1. The geometrical data of the experimentally investigated tubes.

\begin{tabular}{|l|c|c|c|c|c|c|c|c|}
\hline Tube name & $A R$ & $p, \mathrm{~mm}$ & $L, \mathrm{~mm}$ & $A_{\mathrm{s}, \mathrm{i}}, \mathrm{mm}^{2}$ & $A_{\mathrm{s}, \mathrm{o}}, \mathrm{mm}^{2}$ & $D_{\mathrm{h}}, \mathrm{mm}$ & $\begin{array}{l}\delta, \\
\mathrm{mm}\end{array}$ & Inaccuracy in $D_{\mathrm{h}}, \%$ \\
\hline AR1.6 p=7.5 & 1.6 & 7.5 & 250 & 4195.4 & 5873.3 & 5 & 1 & \pm 0.4 \\
\hline AR2.0 p=7.5 & 2.0 & 7.5 & 250 & 4525.2 & 6349.8 & 5 & 1 & \pm 2.8 \\
\hline AR1.6 p=20 & 1.6 & 20.0 & 250 & 4087.5 & 5526.9 & 5 & 1 & \pm 1.8 \\
\hline AR2.0 p=20 & 2.0 & 20.0 & 250 & 4280.2 & 5893.9 & 5 & 1 & \pm 2.9 \\
\hline AR2.2 p=20 & 2.2 & 20.0 & 250 & 4396.8 & 6028.2 & 5 & 1 & \pm 3.6 \\
\hline Straight & - & - & 250 & 3925.0 & 5495.0 & 5 & 1 & - \\
\hline
\end{tabular}

Figure 2 shows three of the tubes that were tested in a counter flow tube-in-shell heat exchanger. 3D models of all of the experimentally investigated tubes are available as supplementary material of this article. The double corrugated tube geometry varies in $A R$ and $p$. The manufacturing process of the tubes may result in higher inner surface roughness of the tubes. Therefore, surface roughness analysis was carried out using an LEXT OLS4100 3D Measuring Laser Microscope made by Olympus Corporation. A sample for the surface roughness analysis was cut along the flow direction of the straight tube. The surface root square mean roughness, $S_{q}$, of a rectangular area 0.62 $\times 6.56 \mathrm{~mm}$ was directly measured according the standard ISO 4287 and found to be $0.013 \mathrm{~mm}$ with the maximum difference between the highest and the lowest measured points of $145.6 \pm 13 \mu \mathrm{m}$. 


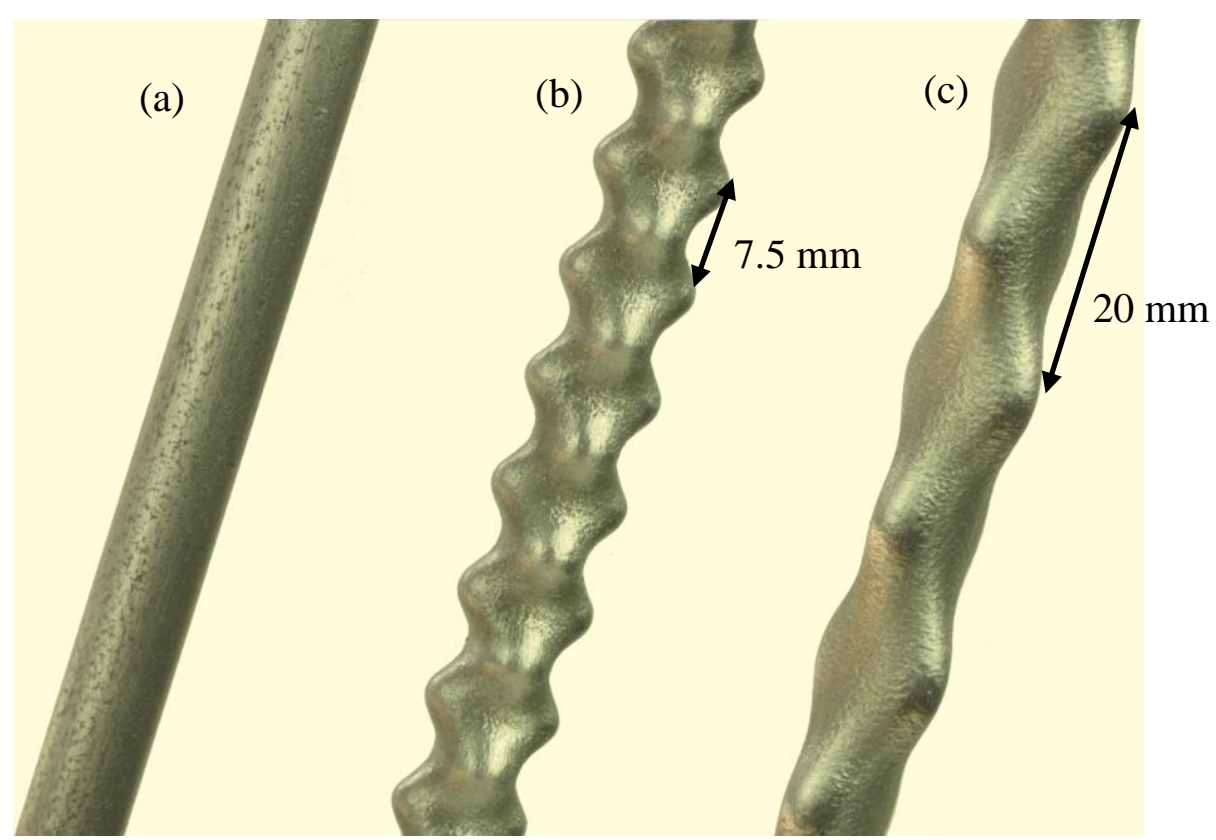

Figure 2. The 3D printed tubes (a) the straight reference tube, (b) double corrugated tube with $A R=2.0$ and $p=7.5 \mathrm{~mm}$,

(c) double corrugated tube with $A R=2.2$ and $p=20.0 \mathrm{~mm}$.

The geometry of the double corrugated tubes constantly impinges on the fluid flow and prevents the development of boundary layers. Modelling showed that the changing wall profile effectively alters the velocity profile near the wall and improves heat transfer along the entire length of the tube [27]. Figure 3 demonstrates how the thermal boundary layers are disturbed in the double corrugated tube with $A R=2.0$ and $p=7.5 \mathrm{~mm}$ and the corresponding straight tube in CFD modelling.

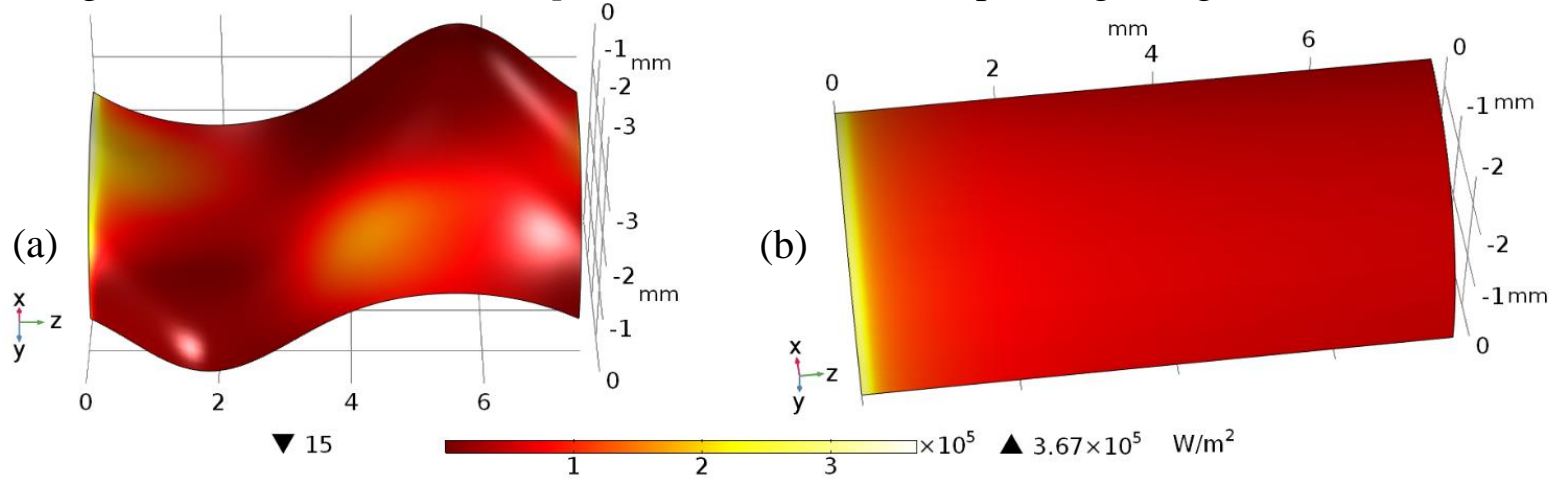

Figure 3. The heat flux in a double corrugated tube (flow rate $0.002 \mathrm{~m}^{3} \mathrm{~h}^{-1}$ ) (a) and a straight (flow rate $0.004 \mathrm{~m}^{3}$ $\mathrm{h}^{-1}$ ) tube (b) at the same pressure drop $\Delta p=1.843 \mathrm{~Pa}$.

One can see that the heat exchange in the double corrugated tube continues over the entire length, while the straight tube experiences the maximum heat flux only in the inlet region. The full description of the modelling procedure and the obtained results are presented in Ref. [27]. For the sake of clarity in this article, it has to be noted that fully hydraulically developed fluid flow with a constant wall temperature condition and a constant pressure difference condition were modelled while the experiments were conducted at developing flow conditions and the wall temperature cannot be considered constant. Finally, a single period of each double corrugated tube with different geometrical characteristics was considered in the model. Experiments, on the other hand, were carried out on tubes with constant length. Note that number of corrugation periods per length of the examined tubes is an integer.

\subsection{The test setup}

Figure 4 shows the tube-in-shell counter-flow heat exchanger in which all the tubes were tested. The connectors (3) shown in Figure 4 (b) of the heat exchanger were machined out of nylon 
and have a conical shape to ensure sealing between the tube and the shell sides. Figure 5 shows the schematic of the full experimental setup.
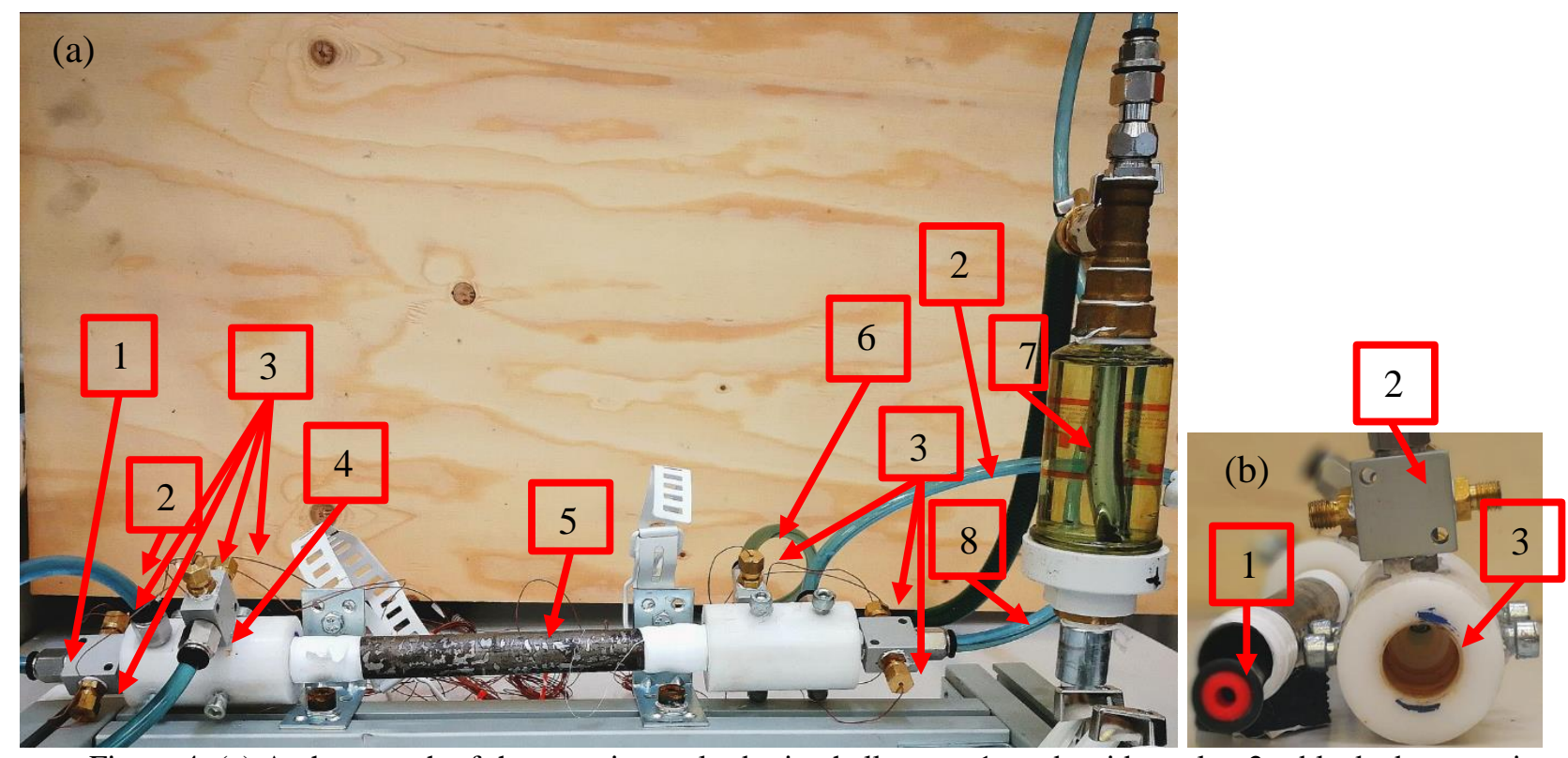

Figure 4. (a) A photograph of the experimental tube-in-shell setup. 1 - tube side outlet; 2 - blocked connections for pressure measurements; 3 - thermocouples; 4 - shell side inlet; 5 - shell (OD $20 \mathrm{~mm}$ ); 6 - shell side outlet; 7 - air separator; 8 - tube side inlet. (b) 1 - 3D printed connector with an O-ring for sealing the tube side in the shell; 2 manifold for mounting thermocouples; 3 - a nylon connector.

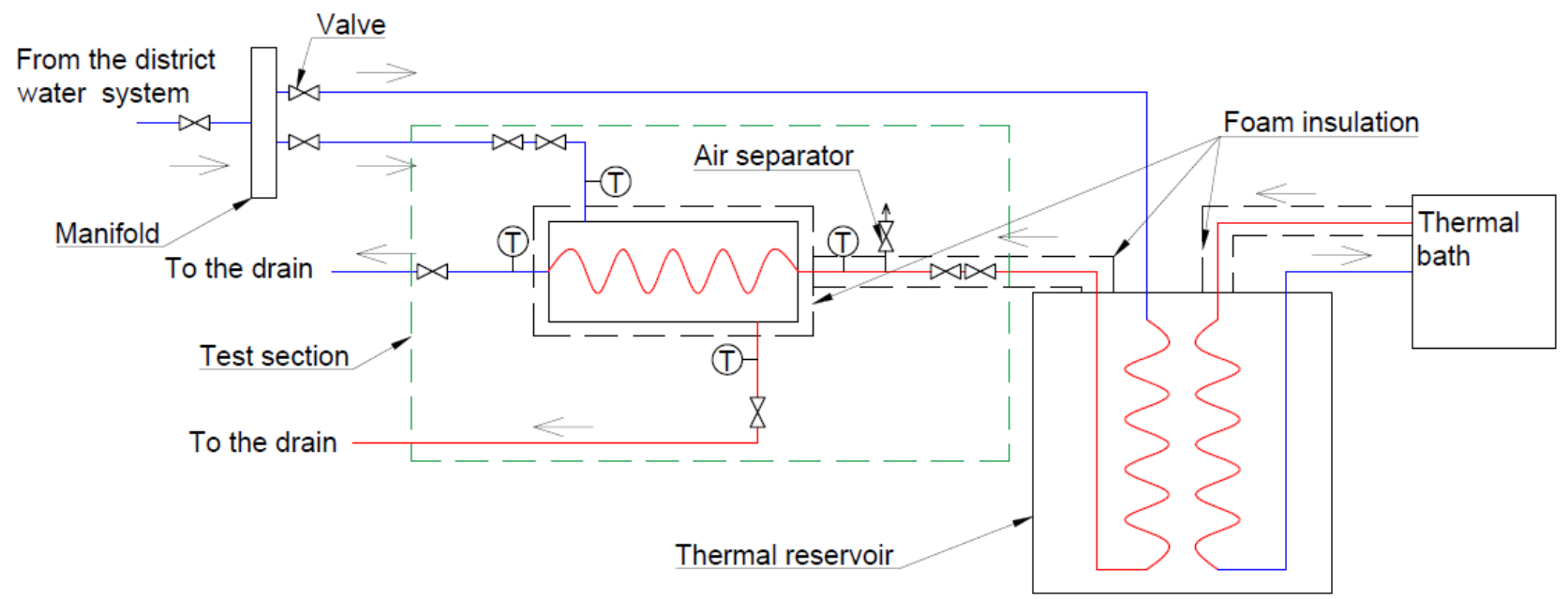

Figure 5. Schematic of the experimental setup for convective heat transfer measurements.

The water for the test rig was supplied from the district water supply system. The water flow was separated into two streams by a manifold with the possibility to regulate/close both flows using valves. A cold-water stream was directly connected to the shell side, which has an inner diameter of $20 \mathrm{~mm}$. Two valves were used to regulate the flow rate. The hot-water side was connected through a thermal reservoir with a copper coil heat exchanger. The water temperature at the thermal reservoir was maintained using a thermal bath. The heated water $\left(T_{\mathrm{hot}} \approx 60{ }^{\circ} \mathrm{C}\right)$ was pushed to the air separator and then to the test section. The flow rate was regulated using two valves at the inlet to the tube and one valve at the outlet of the tube. Mass flow rates were calculated by measuring the mass of water and interval of time, needed to fill a flask, whose mass was determined before the experiments, using a high precision digital balance and a stop watch. This flow regulation technique ensured bubble-free water flow. The temperatures at the inlet and the outlet of the tube and shell sides were measured by two T-type thermocouples at each point. The thermocouples were connected to an NI Ice point reference and the results were logged using LabView. The experimental uncertainty was $\pm 0.1^{\circ} \mathrm{C}$. 
The size of the investigated tubes and the construction of the experimental setup presented additional challenges to the experiments. The thermal experiments were limited to a certain range of $R e$ due to temperature stratification at the outlets when $R e$ was lower than 700 and 1000 on the tube and shell sides, respectively. On the other hand, steady state could not be reached with $R e$ higher than 2500 on the tube side. Finally, the maximum possible $R e$, without compromising accuracy of the mass flow rate measurements, on the shell side was 5000.

Pressure drops in the studied sections were measured by a Coplanar Rosemount ${ }^{\circledR}$ 3051Sseries differential pressure transducer in isothermal conditions. It operated in the range $0-1$ bar with a measurement accuracy of $0.025 \%$ of the calibrated span. The pressure drop was measured at isothermal conditions using a differential manometer. The uncertainty of the differential manometer was $\pm 10 \mathrm{~Pa}$.

\subsection{Data Processing}

The main goal of the present experimental work is to characterize the behaviour of the tested double corrugated tubes. The heat transfer performance and the pressure drop penalty were quantified by means of the Nusselt number $(\mathrm{Nu})$ distribution and friction factor $(f)$ respectively. In the data reduction, $D_{h}$ was used as the characteristic length.

\subsubsection{Heat transfer: parameter estimation approach}

For any parallel flow heat exchanger, the average overall heat transfer coefficient, $U$, referred

$$
U=\frac{Q}{A_{o} \Delta T_{l m}}
$$

where $\Delta T_{l m}$ is the logarithmic mean temperature difference and $Q$ is the heat flow rate. The heat flow rate $Q$ from Eq. (2), can be suitably determined by the energy balance, Eq. (3), for the fluid stream on the tube side.

$$
Q=m_{i} c_{p, i}\left(T_{i, \text { in }}-T_{i, \text { out }}\right)
$$

where $T_{i, \text { in }}$ and $T_{i, \text { out }}$ express the tube-side fluid bulk temperatures evaluated at the inlet and outlet sections, respectively.

The energy balance can also be evaluated on the shell stream (Eq. (4)) but, in this case, some care is needed to measure the bulk temperature, as the temperature difference between the inlet and the outlet is quite small.

$$
Q=m_{o} c_{p, o}\left(T_{o, o u t}-T_{o, \text { in }}\right)
$$

The overall heat transfer coefficient is related to the tube side and shell side fluid convective heat transfer coefficients by Eq. (5).

$$
\frac{1}{U A_{o}}=\frac{1}{h_{i} A_{i}}+R_{w}+\frac{1}{h_{o} A_{o}}
$$

Where $h_{i}$ is the convective heat transfer coefficient of the water flowing in the tube and $h_{o}$ is the convective heat transfer coefficient of the water stream flowing on the shell side, $A_{i}$ and $A_{o}$ are the inner and outer heat transfer surface areas and $R_{w}$ is the thermal resistance of the wall that separates the two fluids, expressed by Eq. (6) for circular tubes. 


$$
R_{w}=\frac{\ln \left(D_{0} / D_{i}\right)}{2 \pi L k_{w}}
$$

Where $L$ the heat exchanger's length, $k_{w}$ is the thermal conductivity of the wall material, which is approximately $k_{w}=150 \mathrm{Wm}^{-1} \mathrm{~K}^{-1}$ [28].

The wall thermal resistance, $R_{w}$, can be assumed known and constant for a given heat exchanger and under a given operating condition. By using the internal $D_{h}$ of the tested tubes as the characteristic length for the tube section, the internal side Nusselt number is expressed by Eq. (7).

$$
N u_{i}=\frac{h_{i} D_{h}}{k_{f}}
$$

Where $k_{f}$ is thermal conductivity of water inside the tube.

It is not easy to predict which is the dominating thermal resistance in Eq. (5) in this case because the internal-side and shell-side heat transfer coefficient are of the same order of magnitude.

In Eq. (5) both $h_{i}$ and $h_{o}$ are generally unknown and they can be suitably determined by adopting a parameter estimation technique under an inverse data processing methodology [29].

The tube and shell side heat transfer coefficients can be correlated in terms of the Nusselt number using Colburn's analogy expressed as in Ref. [30].

$$
\begin{aligned}
& N u_{i}=C_{i} \operatorname{Re}^{\alpha_{i}} \operatorname{Pr}^{\beta_{i}} \\
& N u_{o}=C_{o} \operatorname{Re}^{\alpha_{o}} \operatorname{Pr}^{\beta_{o}}
\end{aligned}
$$

It follows that the characterization of the studied heat exchangers can be described by assuming that in Eq. (5) the unknown variables are $C_{i}, \alpha_{i}, \beta_{i}, C_{o}, \alpha_{o}, \beta_{o}$. In the present case water is the only working fluid. Thus, the Prandtl number does not vary significantly during the tests. Therefore, the value of the coefficients $\beta_{i, o}$ has been assumed equal to a classical value of 0.33 present in many of the Nusselt number correlations that characterized the fluid flow inside straight tube [30]. Both $h_{i}$ and $h_{o}$ could be concurrently estimated under the parameter estimation approach by minimizing the squared errors of the prediction with respect to the experimentally measured values for $U$ [29]. This implies to minimize, under the usual least square approach, the following function:

$$
S\left(C_{i}, \alpha_{i}, C_{o}, \alpha_{o}\right)=\sum_{j=1}^{N}\left[(U)_{e x p, j}-(U)_{c a l c, j}\right]^{2}
$$

Where $N$ is the number of measurements which are performed by varying fluid mass flow rate for both the tube and shell side with the resulting and $U_{\text {calc }}$ is expressed as follows:

$$
U_{\text {calc }}=\frac{1}{A_{o}}\left(\frac{D_{h, i}}{k_{f} A_{i}} \cdot \frac{1}{C_{i} R e^{\alpha_{i} P r^{0.33}}}+R_{w}+\frac{D_{h, o}}{k_{f} A_{o}} \cdot \frac{1}{C_{o} R e^{\alpha_{o} P r^{0.33}}}\right)^{-1}
$$

Then, the parameter estimation procedure applied to the heat transfer characterisation of the studied heat exchanger is represented by the minimisation of the objective function $S$ expressed by Eq. (10) by considering $R e$ as the independent variable and $C_{i}, \alpha_{i}, C_{o}$ and $\alpha_{o}$ as the unknown variables, and all the other properties and geometrical quantities to be known.

\subsubsection{Friction factor}

Regarding the pressure drop, the average Darcy-Weisbach friction factor was calculated as given by Eq. (12).

$$
f=2 \frac{\Delta p D_{h}}{\rho w^{2} L}
$$


Where $w$ is the mean fluid axial velocity and $\Delta p$ is the pressure drop along the tested section of length $L$. Due to the experimental setup configuration, a concentrated pressure drop is present and originates from strong cross sectional area variations that occur in the connectors. Therefore, the full pressure drop, $\Delta p$, in the test region is expressed by Eq. (13).

$$
\Delta p=f \frac{\rho w^{2}}{2 D_{h}} L+\xi \frac{\rho w^{2}}{2}
$$

The first term on the right hand side of Eq. (13) expresses frictional pressure losses, while the second term expresses the concentrated pressure drop. Here $\xi$ is the vorticity [31].

As it is mentioned above, the concentrated pressure is caused by a change in cross-section area where the tested tubes were connected to the test setup and must be the same for all the investigated tubes. This type of pressure drop is caused by a change in kinetic energy of the fluid flow and can be addressed as minor losses, $K_{\mathrm{L}}$ [31,32]. However, the fluid flow is no longer fully developed, once it passes any obstacle. To achieve a fully developed flow again, there must be a smooth region of a length of $10 D_{\mathrm{h}}$ after an obstacle was passed. This is not possible to construct in the test setup and evaluate the pressure drop in the investigated tubes only. Thus, vorticity $\xi$ was employed as a measure for eliminating entrance region effect on pressure drop. Vorticity $\xi$ expresses how big the pressure loss would be until the flow is fully developed [31]. Therefore, pressure drop for a fully developed flow could be evaluated for all the tested tubes. It is important to separate the frictional and concentrated pressure drop in order to enable fair comparison of the friction factor in double corrugated tubes and the equivalent straight tube. Note that for the straight tube only frictional pressure drop component remains after subtraction of the concentrated pressure drop. On the other hand, the remaining pressure drop component for the double corrugated tubes contains frictional and additional pressure loss, caused by tube corrugation. Nevertheless, it is addressed as frictional pressure loss further in the text.

In order to separate frictional and concentrated pressure loss, the $\xi$ value must be determined. Since the influence of the construction of the test setup on the pressure loss is evaluated excluding the geometrical characteristics of the analysed tubes, the value of $\xi$ is unique for every flow regime. For this reason, the experimental data obtained for the straight tube were analysed. Two well-known correlations were used to calculate friction factor $f$ causing the frictional pressure drop. Namely, the Darcy friction factor, given by Eq. (14), and Colebrook correlations, given by Eq. (15), used for the laminar and turbulent flow regimes [32], respectively.

$$
\begin{gathered}
f_{\text {laminar }}=\frac{64}{R e} \\
\frac{1}{\sqrt{f_{\text {turbulent }}}}=-2.0 \log \left(\frac{S_{q} / D}{3.7}+\frac{2.51}{R e \sqrt{f_{\text {turbulent }}}}\right)
\end{gathered}
$$

Where the relative roughness $S_{q} / D=0.0026$ was used for solving the Colebrook equation for $f$ by using MATLAB routine, presented by Clamond [33]. The experimentally obtained pressure measurement data for the straight tube were sorted into laminar $R e \leq 2000$ [32] and turbulent $R e>$ 3500 regimes, the range in between them was considered to be transitional.

Once the frictional and concentrated pressure drop were separated, the $\xi$ values were determined for laminar and turbulent flow regimes using a least square fit method. Friction factor for the experimentally investigated tubes was determined from the frictional pressure loss component that was obtained by subtracting the concentrated pressure drop from the full pressure drop. The obtained $f$ values for all the tubes were fitted to the form given in Eq. (16) [25] using the nonlinear regression approach.

$$
f=K e^{\gamma}
$$


The uncertainty of the predicted friction factor values is expressed in terms of standard error of estimate, $\sigma_{e s t}$, as defined by Taylor [34].

$$
\sigma_{\text {est }}=\sqrt{\frac{\sum\left(f_{\text {exp }}-f_{\text {est }}\right)^{2}}{N-2}}
$$

\subsubsection{Performance evaluation criteria}

The global performance evaluation criteria $(P E C)$ at constant pumping power is the most commonly used approach to evaluate the overall performance of any enhanced geometry. The PEC is calculated as in Ref. [15].

$$
P E C=\frac{N u / N u_{0}}{\left(f / f_{0}\right)^{1 / 3}}
$$

To enable a straightforward comparison of the double corrugated tubes when designing heat exchangers, the presented $N u$ correlations are obtained using geometrical data such as surface area, $A_{s}$, cross-section area, $A_{c}$ and hydraulic diameter, $D_{h}$, of an equivalent straight. Using this approach, the benefits of the enhanced surface area are already included in the comparison. Moreover, Bergles et al., [35] pointed out that it is more convenient to use a nominal geometry for identifying heat transfer augmentation, especially if the enhanced tube is used as a direct replacement of an existing straight tube. It must be mentioned that the maximum enhancement of the surface area in the investigated double corrugated tube was less than $16 \%$, thus it is of less importance. The penalty for the enhanced surface is evaluated via the friction factor, which is obtained from pressure drop measurements.

\section{Results and discussion}

The obtained experimental results for the tube side are presented in terms of correlations of $N u, f$ and $P E C$. The experimental results presented in this study are compared with other state-ofthe-art enhanced geometries. It must be acknowledged that most experimental studies published on enhanced heat transfer in laminar flow regime were conducted under uniform heat flux conditions [18,36-38]. This implies that, considering a straight tube, $N u$ is generally higher due to the experimental boundary conditions [30]. Thus, a more appropriate comparison of the thermal effectiveness of different kinds of enhanced surfaces could be done only by evaluating ratios of enhanced $\mathrm{Nu}$. The experimental studies on AEA tubes and tubes fitted with helical screw-tape reported in Ref. [13,18] are chosen for the comparison because of the most suitable interval of Re. The $N u$ correlation for an AEA tube $\left(N u_{A E A}\right)$ is given by Eq. (19) as in Ref. [13] and for a helical screw-tape $\left(N u_{H S T}\right)$ by Eq. (20) as in Ref. [18].

$$
\begin{aligned}
& N u_{A E A}=0.0615 \operatorname{Re}^{0.76} \operatorname{Pr}_{f}^{1 / 3}\left(\frac{P r_{f}}{P r_{w}}\right)^{0.11} \\
& N u_{H S T}=0.017 \operatorname{Re}^{0.996} \operatorname{Pr} Y^{-0.5437}
\end{aligned}
$$

Where $Y$ is the twist ratio (length of one twist/diameter of the twist). According to Ref. [18], the best performing helical screw-tape had $Y=1.95$. Thus, this value was used for comparison. The $N u$ correlation reported in Ref. [13] is obtained for the AEA tube with $p / D_{o}=2$ and $A R=1.6$. The correlation is valid for a $R e$ range from 500 to 50000 . The $p / D_{o}$ ratio of the double corrugated tubes reported in this study is from 1.1 to 2.9 .

Correlations for $f$ for the corresponding AEA tube $\left(f_{A E A}\right)$ were given by Eq. (21) as in Ref. [13] and for the corresponding helical screw-tape $\left(f_{H S T}\right)$ by Eq. (22) as in Ref. [18].

$$
f_{A E A}=1.54 R e^{-0.32}
$$




$$
f_{H S T}=10.7564 R e^{-0.387} Y^{-1.054}
$$

However, neither of the selected studies report correlations for $N u$ and $f$ of their reference geometries. Moreover, the precise $\operatorname{Pr}$ number of the working fluid and the fluid layer close to the wall are not reported either. Thus, experimental data obtained in this study were correlated using the Eqs. (19-22) with the awareness of increasing uncertainty when comparing results. The ratio of $\operatorname{Pr}$ number of the fluid and the fluid layer at the wall in Eq. (19) is assumed to be 1. Due to above mentioned reasons, the PEC of double corrugated tubes is not compared with the PEC of AEA tube and helical screw-tape.

A qualitative comparison of the experimental and numerical results is also provided in the discussion. The Reader is asked to remember that the modelling boundary conditions in Ref. [27] and the experimental conditions were different, thus quantitative comparison is not possible. Modelling showed that heat transfer performance increased with increasing $A R$ and decreasing corrugation period.

\subsection{Heat transfer results}

The experimental heat transfer results for the straight tube were compared to both the Hausen (Eq. (23)) and the Sieder-Tate (Eq. (24)) correlations for the thermal entry region [39] in the laminar flow regime.

$$
\begin{gathered}
N u_{\text {Hausen }}=3.66+\frac{0.0668\left(\left(D_{h} / L\right) R e P r\right)}{1+0.04\left(\left(D_{h} / L\right) R e P r\right)^{2 / 3}} \\
N u_{\text {Sieder-Tate }}=1.86\left(\frac{\operatorname{RePr}}{L / D_{h}}\right)^{1 / 3}\left(\frac{\mu}{\mu_{w}}\right)^{0.14}
\end{gathered}
$$

Where $\mu$ is the dynamic viscosity of water. The term evaluating the ratio of dynamic viscosities is considered to be one, since the measured temperature difference measured in a straight tube is approximately $10^{\circ} \mathrm{C}$ and the change in viscosity is minor.

Figure 6 shows that the obtained results agree very well with the Hausen correlation, with a confidence of $85 \%$, and with the Sieder-Tate correlation, with a confidence of $95 \%$. This is a good indication that the test setup and the method of data analysis are reliable. The entire estimation procedure was repeated for all the double corrugated tubes: the experimental conditions are reported the Data in Brief article and representative results are shown in Figure 7. 


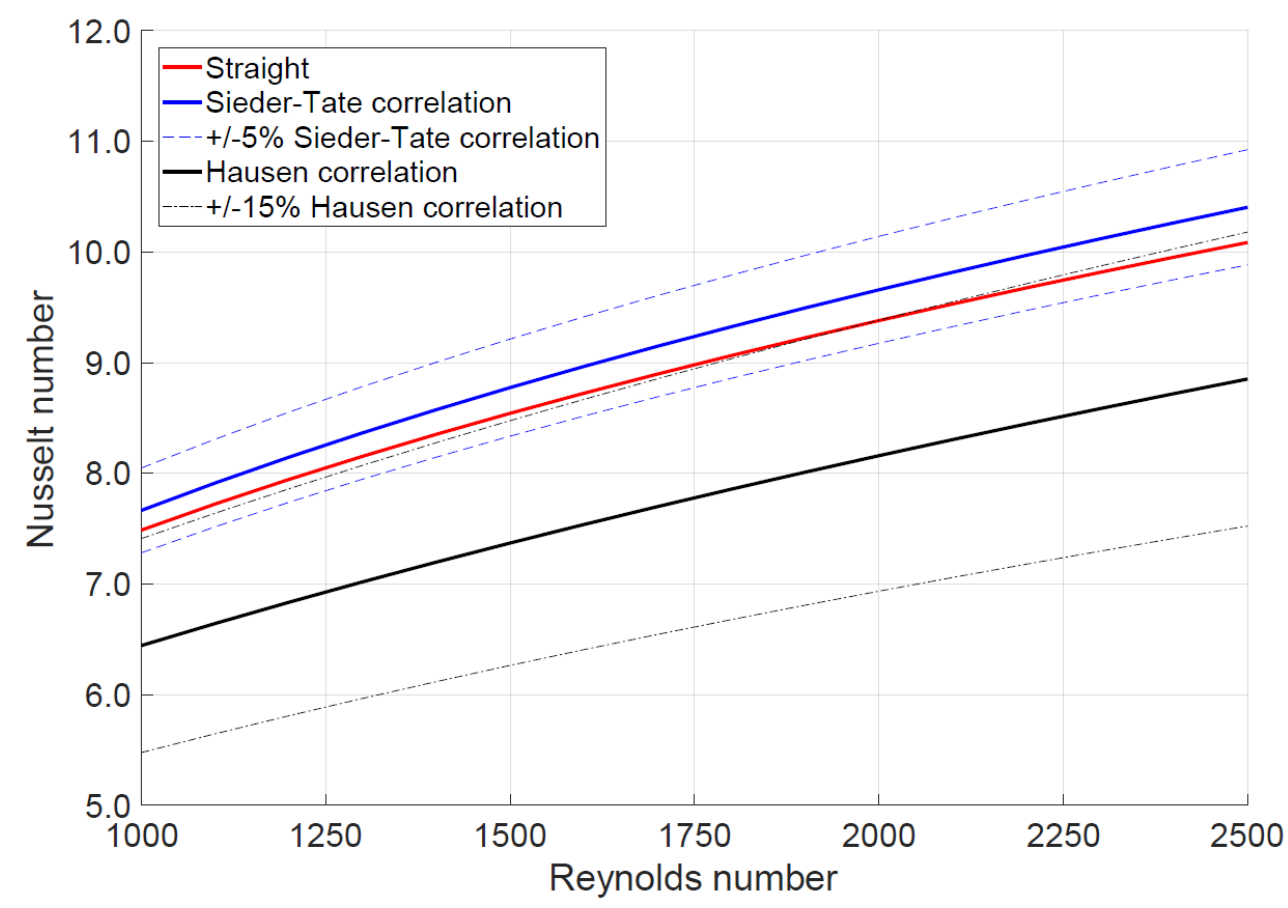

Figure 6. Comparison of $\mathrm{Nu}$ correlation obtained from experimental data for a straight tube and the Hausen and the Sieder-Tate correlations as a function of $R e$.

The accuracy associated with the estimated values was assigned by the parametric bootstrap method $[40,41]$. In this procedure, the term $U_{\text {exp }}$ has been substituted by the distribution:

$$
U_{\text {exp }}=U_{\text {calc }} \cdot(1+\varepsilon)
$$

Where $U_{\text {calc }}$ was obtained from Eq. (11) adopting the heat transfer coefficients found by Eqs. (8-9). In order to find the heat transfer correlations, the $C$ and $\alpha$ values were estimated from the procedure described above. Moreover, $\varepsilon$ represents a uniformly distributed random noise with zero mean and variance $\sigma$. The variance $\sigma$ has been considered equal to the uncertainty related to the measured quantity $\Delta T=T_{i, \text { in }}-T_{i, \text { out }}$. Considering the overall heat transfer coefficient $U_{\text {exp }}$ re-sampled from its probability distribution, as the starting value, the unknowns are calculated by the estimation procedure explained above; this process is repeated many times, and the results are processed using standard statistical techniques for evaluating $95 \%$ confidence intervals (Figure 7). It also represents the uncertainty of the estimation procedure: in order to evaluate the overall uncertainty of the Nusselt number the usual propagation of errors procedure was used [42] considering, in addition to the error of the estimation technique, the uncertainty of temperature measurements, fluid properties and mass flow rate: they were assumed to be $\pm 0.1 \mathrm{~K}, 2 \%$ and $5 \%$ respectively). The obtained correlation coefficients and the uncertainty on $\mathrm{Nu}$ are given in Table 2.

Table 2. Experimentally obtained correlation coefficients for calculating $N u$ inside the tubes and $N u$ uncertainty.

\begin{tabular}{|l|l|l|l|}
\hline Tube name & $C_{i}$ & $\alpha_{i}$ & $\varepsilon_{N u}$ \\
\hline AR1.6 p=7.5 & 0.039 & 0.88 & $\pm 8.0 \%$ \\
\hline AR2.0 p=7.5 & 0.16 & 0.77 & $\pm 8.5 \%$ \\
\hline AR1.6 p=20 & 0.056 & 0.75 & $\pm 9.0 \%$ \\
\hline AR2.0 p=20 & 0.037 & 0.76 & $\pm 11.0 \%$ \\
\hline AR2.2 p=20 & 0.016 & 0.91 & $\pm 9.0 \%$ \\
\hline Straight & 0.52 & 0.33 & $\pm 14.0 \%$ \\
\hline
\end{tabular}

Figure 7 shows that the higher $N u$ values are obtained for double corrugated tubes with shorter corrugation periods. One can see that thermal performance of the double corrugated tubes strongly depends on $p$ while $A R$ is a less significant factor. Generally double corrugated tubes with $p=7.5 \mathrm{~mm}$ show up to $35 \%$ higher $N u$ than double corrugated tubes with $p=20 \mathrm{~mm}$. Figure 7 shows that the double corrugated tube with the $A R=1.6$ and $p=7.5 \mathrm{~mm}$ outperforms the double corrugated tube with the $A R=2.0$ and $p=7.5 \mathrm{~mm}$ once $R e$ is above 2200 . This signifies that more 
intense corrugations are more thermally efficient at lower $R e$. This is in agreement with previous modelling results.

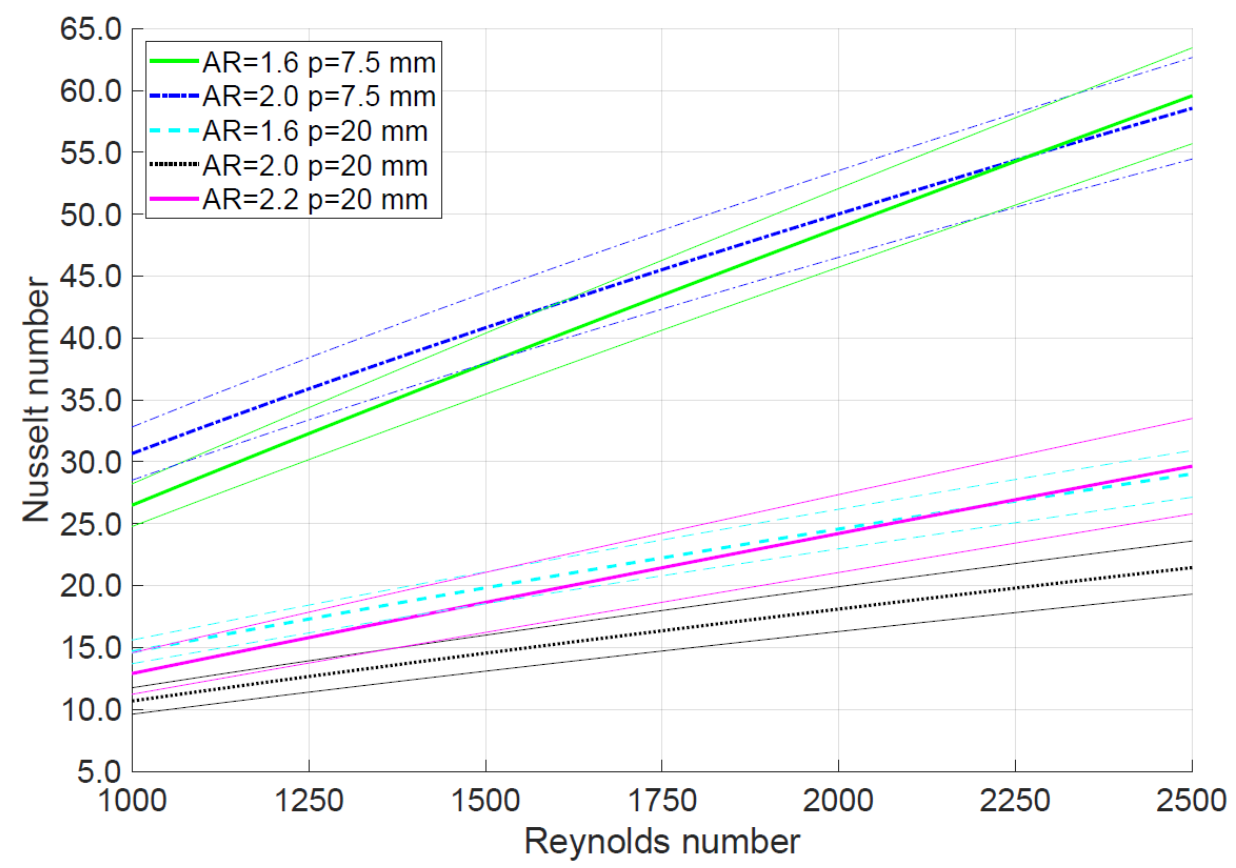

Figure 7. Nusselt number distribution for the tube side and corresponding uncertainty. The Prandtl number used here is $\operatorname{Pr}=3.5$.

However, the double corrugated tubes with $p=20 \mathrm{~mm}$, show that higher thermal performance is obtained for tubes with lower aspect ratios. Namely the double corrugated tubes with $A R=1.6$ shows the highest $N u$ until $R e$ exceeds 2000, then the double corrugated tube with the $A R=2.2$ outperforms it. It is noticeable that the double corrugated tube with $A R=2.0$ shows somewhat lower thermal performance than tubes with $A R=1.6$ and $A R=2.2$. Numerical modelling predicted that performance of the $A R=2.0$ tube should lie between $A R=1.6$ and $A R=2.2$. Several effects could be considered to explain the later findings. One of the contributing factors could be inaccuracy from the manufacturing process, especially geometrical variations on the inner surface. It is hard to manipulate the results since the quality of the inner surface of this tube is unknown. Another explanation could be effects related to transition to turbulent flow, which was not considered in the modelling. Flow visualization tests should be done in order to fully understand and finalize the findings in Figure 7.

The ratio of $N u$ for the double corrugated tubes to the straight tube are shown in Figure 8, which demonstrates that the double corrugated tubes have up to a $500 \%$ increase in $N u$ when $p=$ $7.5 \mathrm{~mm}$ and up to a $200 \%$ increase when $p=20 \mathrm{~mm}$ compared to an equivalent straight tube. It is also noticeable that the $\mathrm{Nu}$ ratio increases with increasing Re. Figure 8 shows more clearly that the thermal efficiency of the double corrugated tubes with $p=7.5 \mathrm{~mm}$ is generally $100 \%$ higher than the double corrugated tubes with $p=20 \mathrm{~mm}$. The performance of an AEA tube and a helical screwtape are also plotted on Figure 8. 


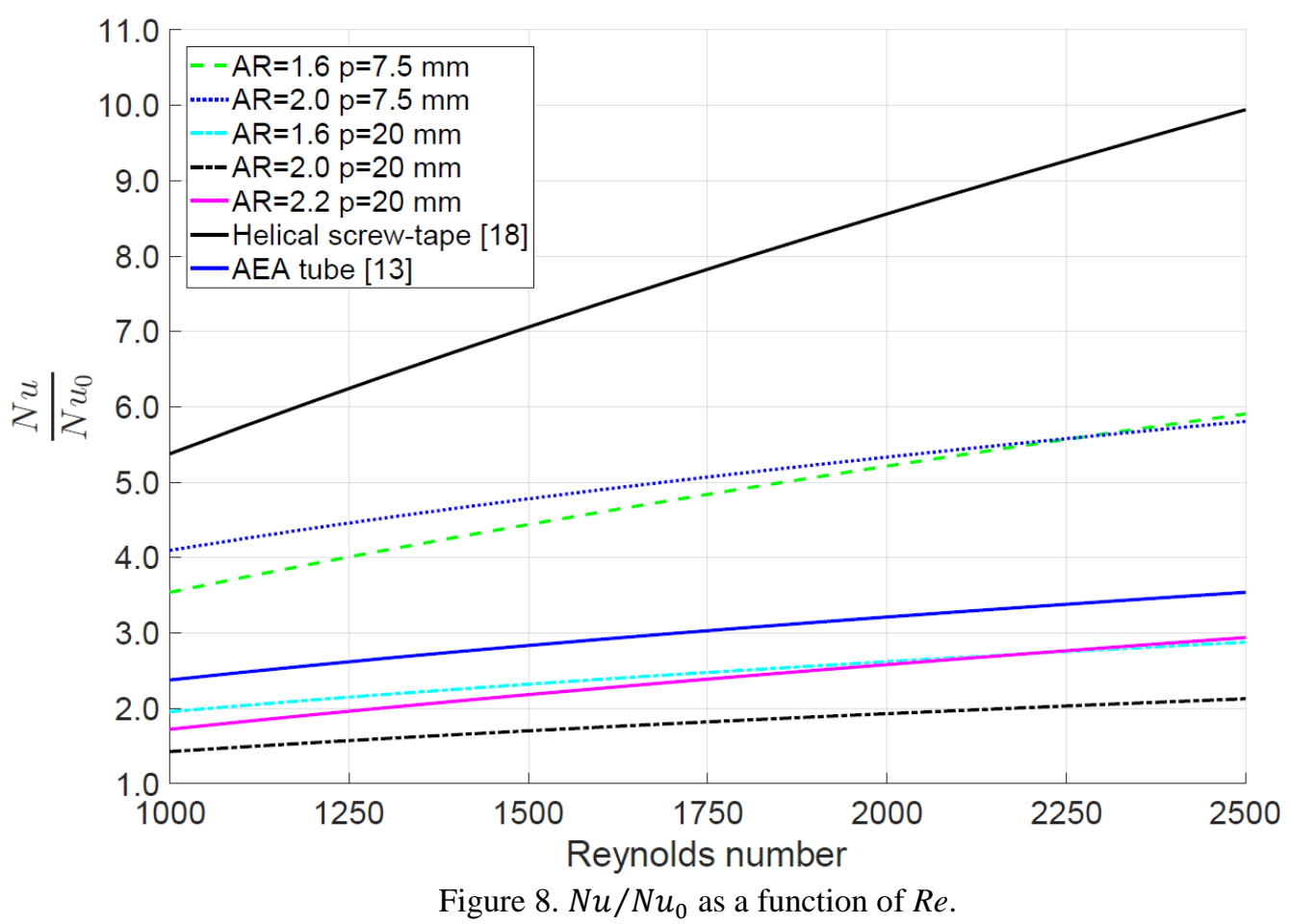

Comparing experimental results of this study with the AEA tube correlation reported in ref. [13], it is seen that the double corrugated tubes with $p=7.5 \mathrm{~mm}$ show significantly higher thermal performance than the AEA tube. On the other hand, double corrugated tubes with $p=20 \mathrm{~mm}$ show similar, however, somewhat lower thermal performance.

Figure 8 shows that the $N u$ ratio for the double corrugated tubes is lower than for the helical screw-tape [18]. However, it is worth noting that the $N u$ correlation for the tube with helical screwtape was obtained at a constant heat flux condition while the correlation for $N u_{0}$ was obtained in the tube-in-shell heat exchanger with water-water system because no equivalent straight tube correlation was given by Ref. [18]. Thus, the thermal efficiency for the helical screw-tape is to some extent over predicted.

The agreements between experimental data and the correlation were checked in terms of the overall heat transfer coefficient, $U$. Figure 9 shows a comparison between experimental and correlated $U$ values for the double corrugated tube with $A R=2.0$ and $p=7.5 \mathrm{~mm}$ inside the tube (a) and inside the shell (b) and experimental values against correlated ones (c). It is found that experimental data and values derived from the correlations are in a very good agreement. 

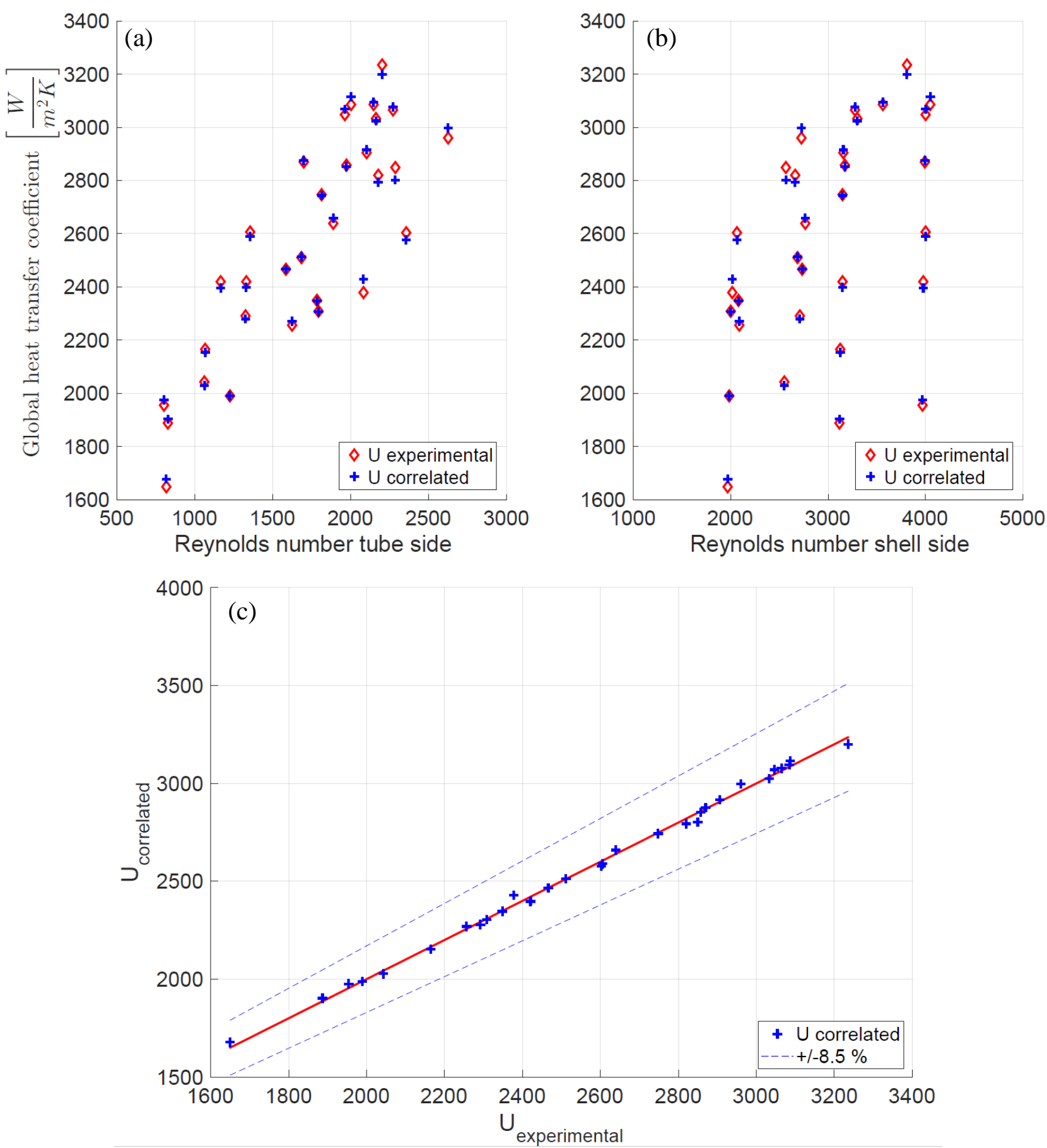

Figure 9. Global heat transfer coefficient $U$ for the double corrugated tube with $A R=2.0 p=7.5 \mathrm{~mm}$ measured experimentally and calculated using the obtained correlations as a function of $R e$ in the tube side (a) and in the shell side (b). Comparison of the measured and predicted $U$ values for the same double corrugated tube (c).

\subsection{Pressure measurement results}

Figure 10 shows a comparison of experimentally measured friction factors for the straight tube when the $\xi$ value is subtracted from the measured values. The corrected experimental data for the straight tube were also compared with Petukhov's correlation as given in Ref. [30], which is valid in a range of $3000 \lesssim R e \lesssim 5 \cdot 10^{6}$.

$$
f_{\text {Petukhov }}=(0.790 \ln R e-1.64)^{-2}
$$

Figure 10 shows an excellent agreement between the corrected experimental data and classical theoretical correlations. The determined values are $\xi=1.3$ for the turbulent regime and $\xi=$ 2.9 for the laminar regime in a straight tube. The $R e$ range from 200 to 3500 is considered the 
transition region for the straight tube and a spline curve is used to represent $f$ in this region for plotting purposes when comparing friction factor in the straight tube to corrugated ones. The obtained $\xi$ values agrees well with the data presented by Nakayama and Boucher [31]. It was pointed out by several authors that flow transition in corrugated tubes occurs much earlier than in a straight tube [13,25], finding that the $R e$ transition value varies from 500 to 800 depending on corrugation intensity [25]. The experimental data presented in this study are in $R e$ interval from 1000 to 2500, thus the flow in double corrugated tubes is considered turbulent and a single value of $\xi=1.3$ was used to normalize the friction factor for the double corrugates tubes.

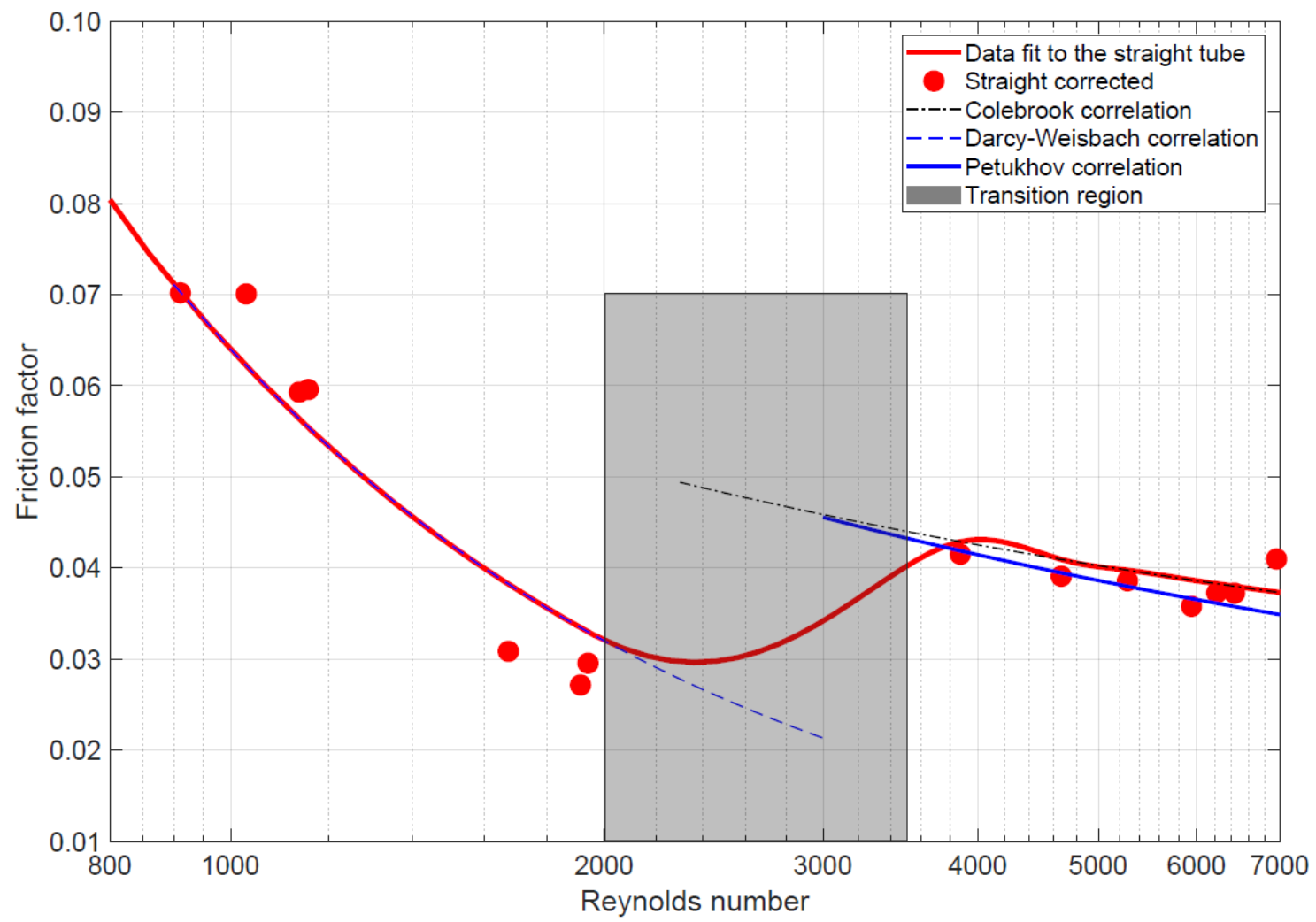

Figure 10. Comparison of the corrected experimental friction factor with Darcy-Weisbach and Colebrook correlations for laminar and turbulent flow regimes in the straight tube, respectively.

The pressure measurements were conducted at isothermal flow conditions on a dedicated rig. Figure 11 shows the corrected experimental $f$ as a function of $R e$. The obtained coefficients of data fit and standard error of estimate are given in Table 3.

Table 3. Data fit coefficients for friction factor and standard error of estimate.

\begin{tabular}{|l|l|l|l|}
\hline \multicolumn{1}{|c|}{ Tube name } & $K$ & $\gamma$ & $\sigma_{\text {est }}$ \\
\hline $\mathrm{AR} 1.6 \mathrm{p}=7.5$ & 1.22 & -0.17 & $\pm 1.97 \%$ \\
\hline $\mathrm{AR} 2.0 \mathrm{p}=7.5$ & 1.17 & -0.12 & $\pm 2.24 \%$ \\
\hline $\mathrm{AR} 1.6 \mathrm{p}=20$ & 10.0 & -0.57 & $\pm 0.35 \%$ \\
\hline $\mathrm{AR} 2.0 \mathrm{p}=20$ & 7.66 & -0.54 & $\pm 0.94 \%$ \\
\hline $\mathrm{AR} 2.2 \mathrm{p}=20$ & 5.94 & -0.52 & $\pm 0.73 \%$ \\
\hline Straight $(700 \leq R e<2000)$ & 581 & -1.31 & $\pm 0.81 \%$ \\
\hline Straight $(3000<R e \leq 6400)$ & 0.21 & -0.20 & $\pm 0.10 \%$ \\
\hline
\end{tabular}

Figure 11 shows the corrected experimental $f$ for the double corrugated tubes and the results of nonlinear regression analysis. From Figure 12 it is clear that the highest $f$ values are obtained for the most corrugated tubes. It can be seen that similar values of $f$ are obtained for all the tubes with $p$ $=20 \mathrm{~mm}$ regardless of $A R$. However, Figure 12 shows that, for the double corrugated tubes with $p=$ $7.5 \mathrm{~mm}$, an increase in $A R$ leads to greater $f$ values. Figure 12 shows that for the most corrugated tube with $A R=2.0$ and $p=7.5 \mathrm{~mm}, f$ increases up to 17 times at laminar-transition $R e$ region, while for all the tubes with $p=20 \mathrm{~mm}, f$ increases up to 4 times at the same $R e$. 


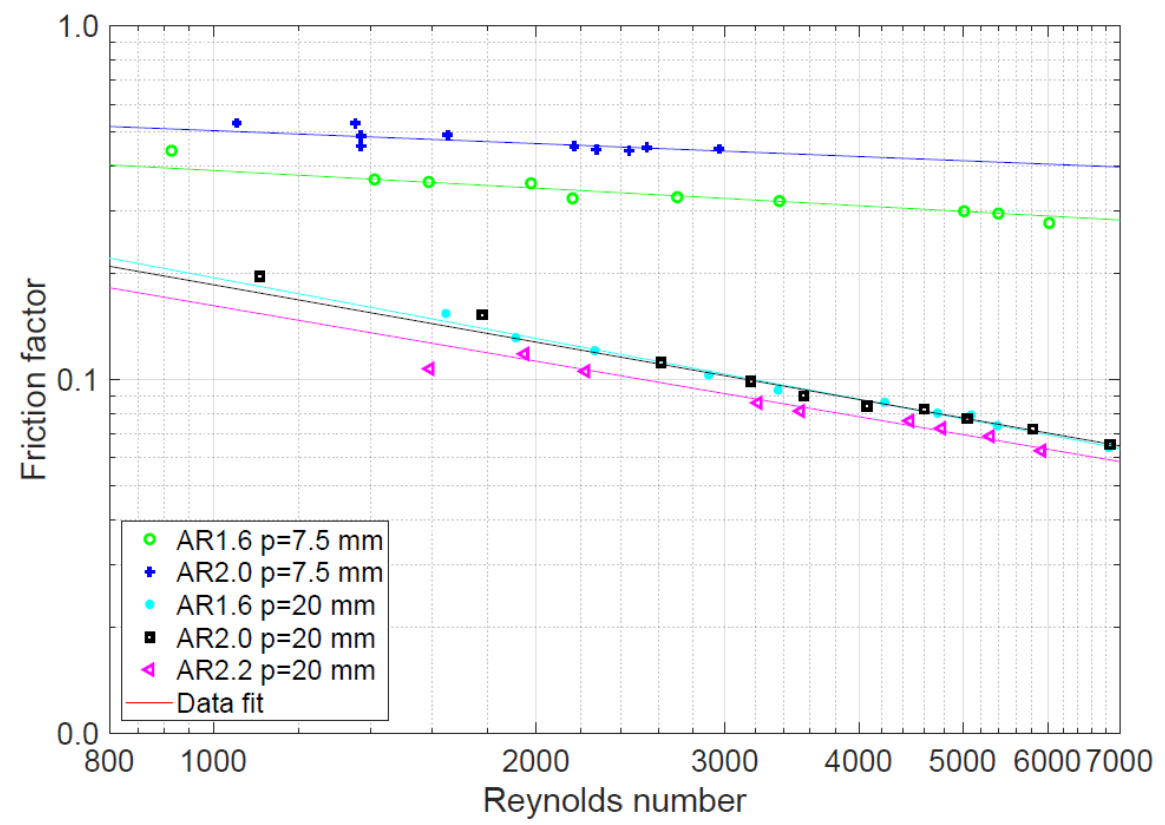

Figure 11. The friction factor, $f$, as a function of $R e$ for double corrugated tubes.

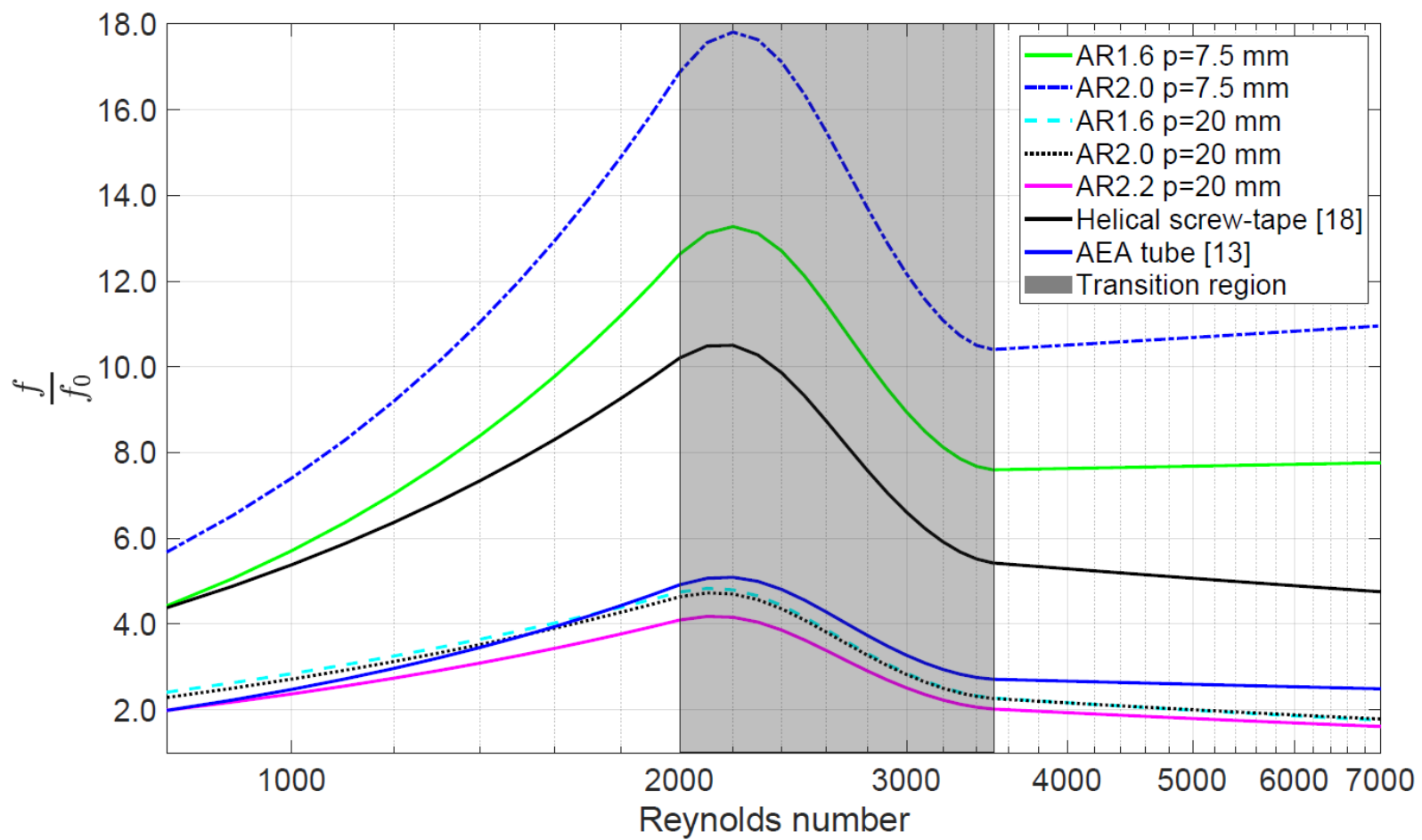

Figure 12. The ratio of $f / f_{0}$ as a function of $R e$. Note that the transition $R e$ is considered to be 2000 for the straight tube.

The ratio of $f$ for the double corrugated tubes is compared to other state-of-the-art geometries. Figure 12 demonstrates that the $f$ ratio for double corrugated tubes with $p=20 \mathrm{~mm}$ and the AEA tube is similar, however, somewhat lower in the turbulent flow region. Moreover, with increasing $R e, f$ decreases faster for the double corrugated tubes with $p=20 \mathrm{~mm}$, than for the AEA tube. This finding shows that the smoother geometrical transition between ellipse-based flow cross-section leads to lower $f$ in comparison with the geometry of the AEA tubes. It is noticeable that the experimental results were correlated with single expression in a range of $R e$ from 800 to 7000 for the double corrugated tubes. This was also found by in Ref. [13] for AEA tubes. 
The ratio of $f$ for a tube fitted with the helical screw-tape [18] is somewhat similar, however lower when compared to the double corrugated tubes with $p=7.5 \mathrm{~mm}$. This is especially noticeable in the turbulent flow region.

The simulations, described in Ref. [27], were performed at constant $\Delta p$, thus the hydraulic performance of the double corrugated tubes was analysed in terms of volumetric flow reduction. Generally, the predicted flow resistance of double corrugated tubes increases for higher $A R$ and smaller $p$.

\subsection{Evaluation of the global performance}

The overall performance of the double corrugated tubes was evaluated at constant pumping power using $P E C$. Figure 13 demonstrates that the overall performance of the double corrugated tubes is up to $160 \%$ higher than the straight tube. It is noticeable that the double corrugated tubes with shorter period demonstrate higher $P E C$ values than tubes with a longer period. Comparison of Figure 8, Figure 12 and Figure 13 suggests that the thermal performance of the double corrugated tubes is more significant than the friction factor when evaluating $P E C$ of the double corrugated tubes with $p=20 \mathrm{~mm}$. However, for the double corrugated tubes with $p=7.5 \mathrm{~mm}$ the friction factor compromises the $P E C$ the most.

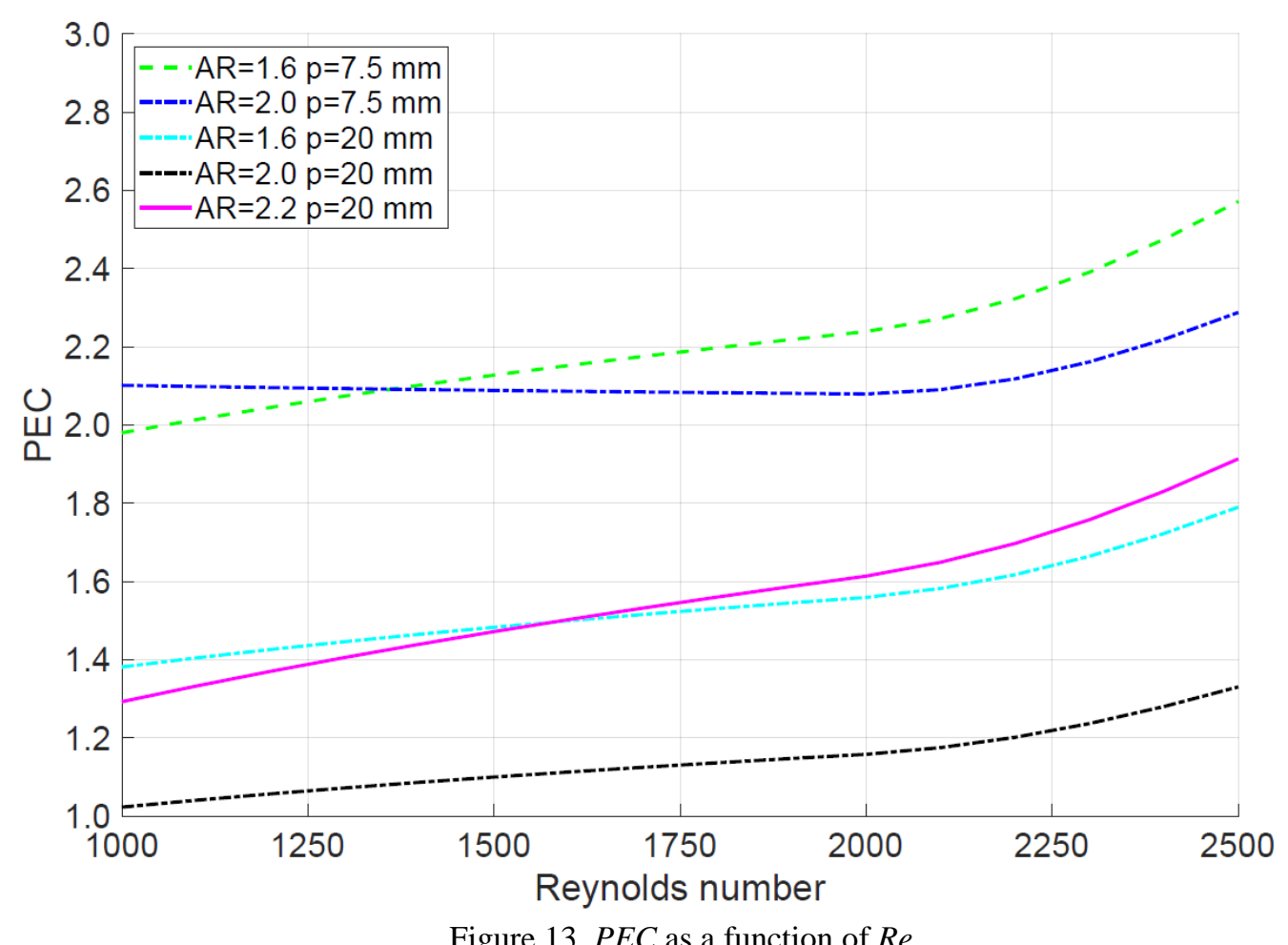

Finally it is worth to mention that the predictions of numerical simulations reported in Ref. [27] generally agree with the experimental $P E C$ results. Both experimental results and numerical predictions agree that $P E C$ is the highest for the double corrugated tubes with $A R=1.6$ when $p=$ $7.5 \mathrm{~mm}$ and $A R=2.2$ when $p=20 \mathrm{~mm}$. However, $P E C$ values predicted by CFD modelling are lower than obtained experimentally. This is due to different boundary conditions of the model and experiment.

\section{Conclusions}

Five double corrugated tubes, whose geometry is inspired by vascular heat exchangers found in fish such as the opah, were experimentally investigated in a tube-in-shell heat exchanger at low $R e$ and compared to other state-of-the-art enhanced heat transfer geometries. The double corrugated tubes, presented in this study, demonstrate superior thermal and global thermo-hydraulic efficiency 
compared to AEA tubes, however thermal performance of the previous tubes is lower when compared to a tube fitted with a helical screw-tape.

Experimental results demonstrate that the double corrugated tubes significantly outperform the equivalent straight tube in the tested $R e$ region. The thermal performance of the double corrugated tubes is up to $500 \%$ higher than a straight tube. The heat transfer benefit comes at a cost of increased pressure drop, but the global thermo-hydraulic performance is up to $160 \%$ higher than an equivalent straight tube, indicating that the overall thermal performance is enhanced.

Tubes with shorter corrugation period are shown to be generally more efficient. For the tubes tested, the corrugation period has a higher impact on the thermal and overall performance than the aspect ratio. The novel geometry of the double corrugated tubes demonstrates superior thermal performance in comparison with the AEA tubes, although somewhat lower than spirally corrugated tubes with twisted tape inserts. However, most of the reported experimental results on performance of enhanced surfaces were obtained in higher $R e$ flow regimes, where data does not exist for the double corrugated tubes. In order to conduct comprehensible comparison of the performance of double corrugated tubes and other enhanced surfaces, deeper experimental investigation is required. Importantly, the first experimental results, obtained for double corrugated tubes, encourage future research efforts and provide the possibility of more detailed comparisons with other enhanced surfaces. Future studies on fouling behaviour, additional fluids, and two-phase flow could give a better characterization of the double corrugated tubes.

Experiments show that the double corrugated tubes are a promising geometry for enhanced heat transfer. Although the geometry presented here is based on tubes, the concept of holding the hydraulic diameter of the flow cross section constant while varying the geometry can be applied to plate heat exchangers, porous media and other heat transfer applications. Further improvements in performance may be realized by optimization of the corrugation pattern or by using non-elliptical cross sections.

\section{Acknowledgement}

The Authors would like to thank Master student Mattia Scazzina and Professors Romoli and Lutey from University of Parma for their help conducting the experiments. The work was partially supported by the Emilia-Romagna Region (POR-FESR 2014-2020): "Applicazione delle micro/nanotecnologie per lo sviluppo di componenti innovativi per gli impianti di condizionamento" - NANOFANCOIL).

6. References

[1] B. Bhushan, Biomimetics: lessons from nature-an overview, Philos. Trans. R. Soc. A Math. Phys. Eng. Sci. 367 (2009) 1445-1486.

[2] C. Mattheck, K. Bethge, J. Schäfer, Safety factors in trees, J. Theor. Biol. 165 (1993) 185189.

[3] E. Arzt, S. Gorb, R. Spolenak, From micro to nano contacts in biological attachment devices, Proc. Natl. Acad. Sci. 100 (2003) 10603-10606.

[4] B. Dean, B. Bhushan, Shark-skin surfaces for fluid-drag reduction in turbulent flow: A review, Philos. Trans. R. Soc. A Math. Phys. Eng. Sci. 368 (2010) 4775-4806.

[5] P.F. Scholander, V. Walters, R. Hock, L. Irving, Body insulation of some arctic and tropical mammals and birds, Biol. Bull. 99 (1950) 225-236.

[6] K. Johansen, C. Bech, Heat conservation during cold exposure in birds (vasomotor and respiratory implications), Polar Res. 1 (1983) 259-268.

[7] K.A. Dickson, J.B. Graham, Evolution and consequences of endothermy in fishes, Physiol. Biochem. Zool. 77 (2004) 998-1018. 
[8] N.C. Wegner, O.E. Snodgrass, H. Dewar, J.R. Hyde, Whole-body endothermy in a mesopelagic fish, the opah, Lampris guttatus, Science (80-. ). 348 (2015) 786-789.

[9] E.D. Stevens, H.M. Lam, J. Kendall, Vascular anatomy of the counter-current heat exchanger of skipjack tuna, J. Exp. Biol. 61 (1974) 145-153.

[10] P. Börnert, D. Jensen, Coronary artery imaging at $0.5 \mathrm{~T}$ using segmented 3D echo planar imaging, Magn. Reson. Med. 34 (1995) 779-785.

[11] E. Jantsch, Tubular heat transfer aparatus, USA Patent 2663321, 1953.

[12] S. Rainieri, G. Pagliarini, Convective heat transfer to orange juice in smooth and corrugated tubes, Int. J. Heat Technol. 15 (1997) 69-75.

[13] J.A. Meng, X.G. Liang, Z.J. Chen, Z.X. Li, Experimental study on convective heat transfer in alternating elliptical axis tubes, Exp. Therm. Fluid Sci. 29 (2005) 457-465.

[14] J.F. Fan, W.K. Ding, J.F. Zhang, Y.L. He, W.Q. Tao, A performance evaluation plot of enhanced heat transfer techniques oriented for energy-saving, Int. J. Heat Mass Transf. 52 (2009) 33-44.

[15] R.L. Webb, N.H. Kim, Principles of enhanced heat transfer, $2^{\text {nd }}$ ed., Taylor and Francis CRC ebook account, Abingdon, Great Britain, 1994.

[16] Y. Dong, L. Huixiong, C. Tingkuan, Pressure drop, heat transfer and performance of singlephase turbulent flow in spirally corrugated tubes, Exp. Therm. Fluid Sci. 24 (2001) 131-138.

[17] S. Pethkool, S. Eiamsa-ard, S. Kwankaomeng, P. Promvonge, Turbulent heat transfer enhancement in a heat exchanger using helically corrugated tube, Int. Commun. Heat Mass Transf. 38 (2011) 340-347.

[18] P. Sivashanmugam, S. Suresh, Experimental studies on heat transfer and friction factor characteristics of laminar flow through a circular tube fitted with helical screw-tape inserts, Appl. Therm. Eng. 26 (2006) 1990-1997.

[19] V. Zimparov, Enhancement of heat transfer by a combination of three-start spirally corrugated tubes with a twisted tape, Int. J. Heat Mass Transf. 44 (2001) 551-574.

[20] S. Laohalertdecha, S. Wongwises, The effects of corrugation pitch on the condensation heat transfer coefficient and pressure drop of R-134a inside horizontal corrugated tube, Int. J. Heat Mass Transf. 53 (2010) 2924-2931.

[21] S. Pal, S.K. Saha, Experimental investigation of laminar flow of viscous oil through a circular tube having integral axial corrugation roughness and fitted with twisted tapes with oblique teeth, Heat Mass Transf. Und Stoffuebertragung. 51 (2015) 1189-1201.

[22] S. Rainieri, F. Bozzoli, L. Cattani, G. Pagliarini, Compound convective heat transfer enhancement in helically coiled wall corrugated tubes, Int. J. Heat Mass Transf. 59 (2013) $353-362$.

[23] S. Mac Nelly, W. Nieratschker, M. Nadler, D. Raab, A. Delgado, Experimental and numerical investigation of the pressure drop and heat transfer coefficient in corrugated tubes, Chem. Eng. Technol. 38 (2015) 2279-2290.

[24] A. Harleß, E. Franz, M. Breuer, Experimental investigation of heat transfer and friction characteristic of fully developed gas flow in single-start and three-start corrugated tubes, Int. J. Heat Mass Transf. 103 (2016) 538-547.

[25] S. Rainieri, A. Farina, G. Pagliarini, Experimental investigation of heat transfer and pressure drop augmentation for laminar flow in spirally enhanced tubes, Proc. $2^{\text {nd }}$ Eur. Therm. $14^{\text {th }}$ UIT Natl. Heat Transf. Conf. Ed. (1996) 203-209. 
[26] A. Harleß, E. Franz, M. Breuer, Heat transfer and friction characteristics of fully developed gas flow in cross-corrugated tubes, Int. J. Heat Mass Transf. 107 (2017) 1076-1084.

[27] K. Navickaitè, L. Cattani, C.R.H. Bahl, K. Engelbrecht, Elliptical double corrugated tubes for enhanced heat transfer, Int. J. Heat Mass Transf. 128 (2019) 363-377.

[28] D. Martinez-Maradiaga, O. Mishin, K. Engelbrecht, Thermophysical properties of AlSi ${ }_{10} \mathrm{Mg}$ products obtained by metal additive manufacturing, (n.d.).

[29] J. V. Beck, K.J. Arnold, Parameter estimation in engineering and science (probability \& mathematical statistics), John Wiley \& Sons Inc, New York, 1977.

[30] T.L. Bergman, A.S. Lavine, F.P. Incropera, D.P. Dewitt, Introduction to heat transfer, $6^{\text {th }}$ ed, 2014.

[31] Y. Nakayama, R.F. Boucher, Introduction to fluid mechanics, Butterworth-Heinemann, Oxford, UK, 2000.

[32] B.R. Munson, D.F. Young, T.H. Okiishi, Fundamentals of fluid mechanics, $4^{\text {th }}$ ed., John Wiley \& Sons Inc, Ames, USA, 2002.

[33] D. Clamond, Efficient resolution of the colebrook equation, Ind. Eng. Chem. Res. 48 (2009) 3665-3671.

[34] J.R. Taylor, Introduction to error analysis, $2^{\text {nd }}$ ed., Maple-Vail book manufacturing group, California, USA, USA, 1997.

[35] A.E. Bergles, A.R. Blumenkrantz, J. Taborek, Performance evaluation criteria for enhanced heat transfer surfaces, in: $5^{\text {th }}$ Int. Heat Transf. Conf., Tokyo, Japan, 1974.

[36] Z.S. Kareem, S. Abdullah, T.M. Lazim, M.N. Mohd Jaafar, A.F. Abdul Wahid, Heat transfer enhancement in three-start spirally corrugated tube: Experimental and numerical study, Chem. Eng. Sci. 134 (2015) 746-757.

[37] S.K. Saha, U.N. Gaitonde, A.W. Date, Heat transfer and pressure drop characteristics of laminar flow in a circular tube fitted with regulary spaced twisted-tape elements, Exp. Therm. Fluid Sci. (1989) 310-322.

[38] S.K. Saha, B.N. Swain, G.L. Dayanidhi, Friction and thermal characteristics of laminar flow of viscous oil through a circular tube having axial corrugations and fitted with helical screwtape inserts, J. Fluids Eng. 134 (2012) 051210.

[39] F.P. Incropera, D.P. DeWitt, T.L. Bergman, A.S. Lavine, Fundamentals of heat and mass transfer, $6^{\text {th }}$ ed., John Wiley \& Sons, Inc., United States of America, 2007.

[40] B. Efron, The jackknife, the bootstrap and other resampling plans, Society for Industrial and Applied Mathematics, 1982.

[41] B. Blackwell, J. V. Beck, A technique for uncertainty analysis for inverse heat conduction problems, Int. J. Heat Mass Transf. 53 (2010) 753-759.

[42] S.J. Kline, F.A. McClintok, Describing uncertainties in single-sample experiments, Mech. Eng. (1953). 